ASSESSMENT, ALLOCATION, AND MANAGEMENT OF HOME AND COMMUNITY CARE SERVICES FOR MEDICALLY COMPLEX CHILDREN: A CASE STUDY

by

David Salib, RN, Hon. BSc, BScN

\author{
A thesis \\ presented to Ryerson University \\ in partial fulfillment of the \\ requirements in the degree of \\ Master of Nursing \\ in the Program of Nursing
}

Toronto, Ontario, Canada, 2010

C Copyright by David Salib (2010) 


\section{Author's Declaration}

I hereby declare that I am the sole author of this thesis or dissertation.

I authorize Ryerson University to lend this thesis or dissertation to other institutions or individuals for the purpose of scholarly research.

\section{Signature}

I further authorize Ryerson University to reproduce this thesis or dissertation by photocopying or by other means, in total or in part, at the request of other institutions or individuals for the purpose of scholarly research.

\section{Signature}




\title{
ASSESSMENT, ALLOCATION, AND MANAGEMENT OF HOME AND COMMUNITY CARE SERVICES FOR MEDICALLY COMPLEX CHILDREN: A CASE STUDY
}

\author{
Abstract \\ David Salib, RN, Hon. BSc, BScN \\ Master of Nursing, Ryerson University, Toronto, 2010
}

This study examines the experiences of CCAC Care Coordinators when assessing, allocating, and managing medically complex children who require home and community care services. A case-study design was implemented, employing a focus group with seven Care Coordinators and an analysis of the 14 Local Health Integration Networks (LHINs) Integrated Health Service Plans (IHSPs) across Ontario. Three major findings arose from the study. First, families are experiencing increased levels of burden related to the child's care responsibilities. Second, there remains a health human resource shortage of individuals with a specialization in paediatrics in the home and community sector. Third, Care Coordinators function as street-level bureaucrats when allocating publicly funded services without the use of a standardized assessment tool. Ultimately, a model of care needs to be implemented supporting a balanced approach to assessment, utilizing standard assessment tools while providing a means for Care Coordinators to utilize their expertise in allocating services. 


\section{Acknowledgements}

I would like extend my sincere gratitude and appreciation for the continued support, guidance and commitment from my thesis supervisor Dr. Karen Spalding. Throughout the entire process you have always encouraged me to remain focused. I am extremely indebted to you for all that you have done. A sincere thank you to my thesis committee member Dr. Daria Romaniuk for your dedication and expertise for making this thesis possible.

I would like to thank all of the Care Coordinators that participated and took the time to help me understand their roles and helped make this research possible.

A very special thank you to my funding sources: Canadian Institutes of Health Research, SickKids Foundation, and Ryerson University that have supported this research.

Lastly, but most importantly, I would also like to thank my family, friends, classmates and colleagues for all their encouragement and belief in me. 


\section{Table of Contents}

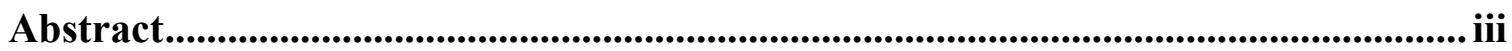

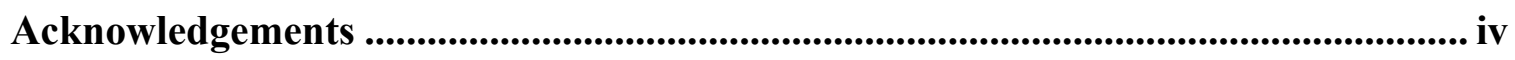

Chapter 1 - Introduction.................................................................................. 1

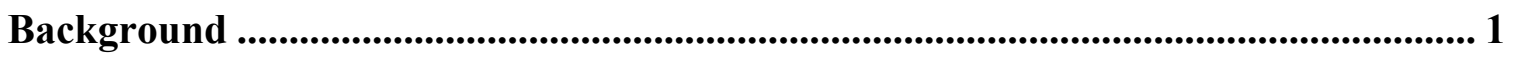

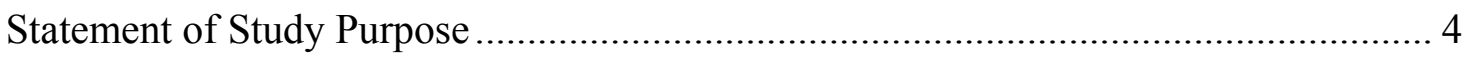

Chapter 2 - Policy Context and Literature Review ................................................... 5

Policy Context .................................................................................................... 5

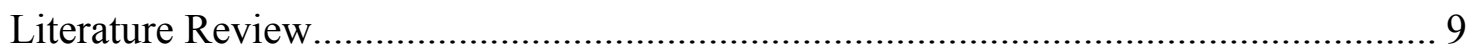

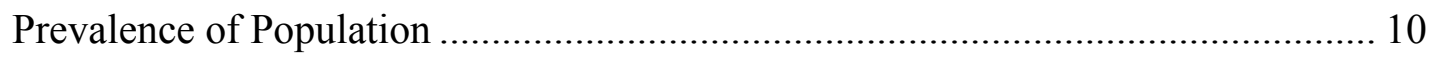

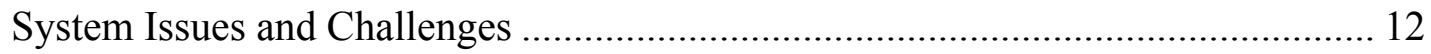

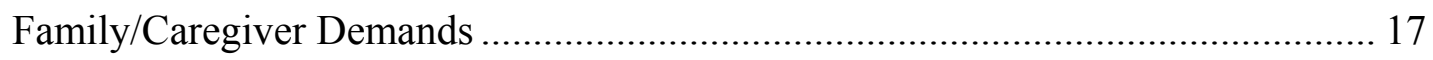

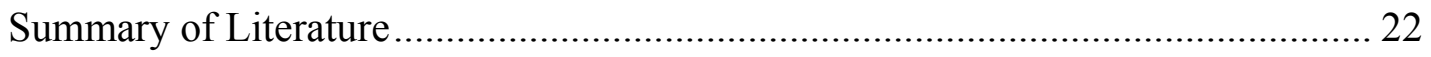

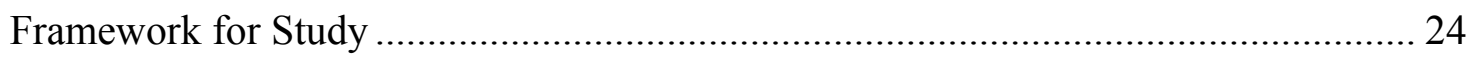

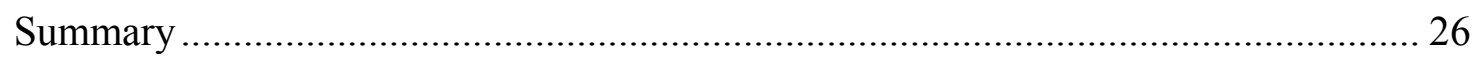

Chapter 3 - Methodology and Procedures....................................................................... 28

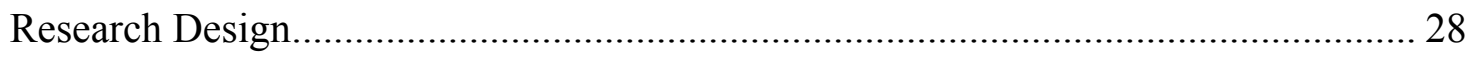

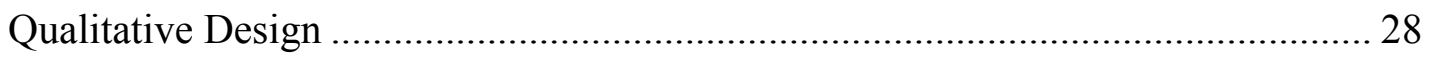

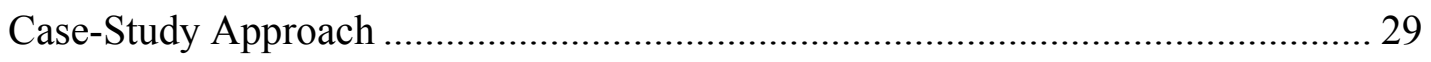

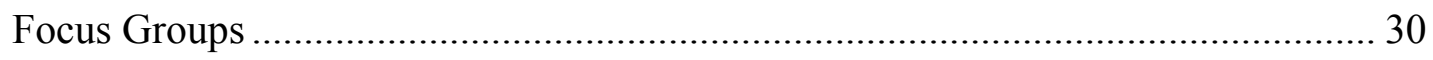

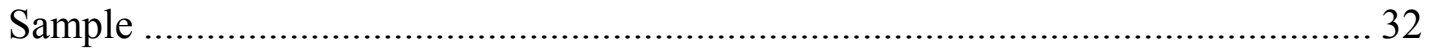

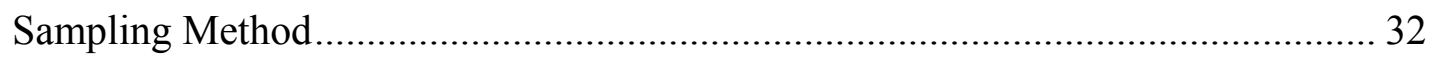

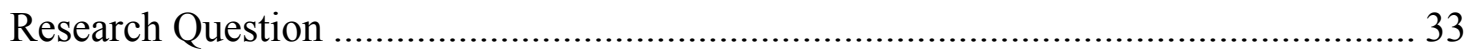




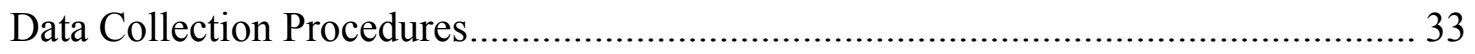

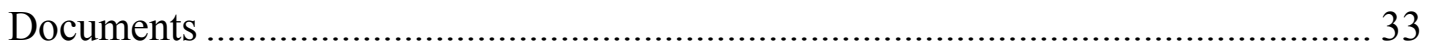

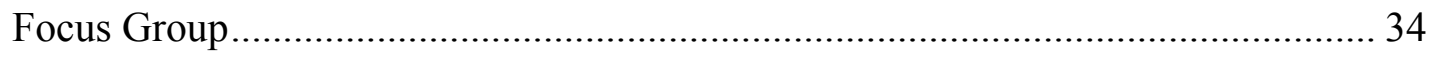

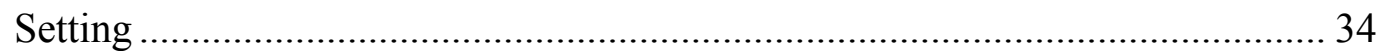

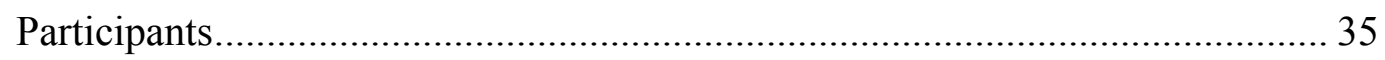

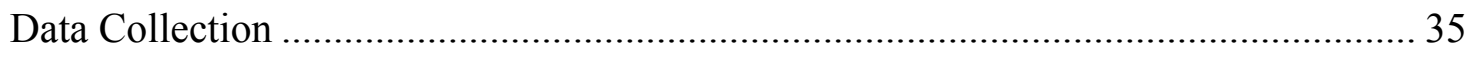

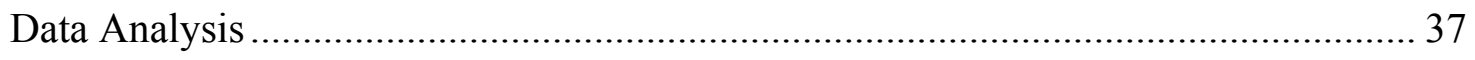

Chapter 4 - Findings ........................................................................................................................ 40

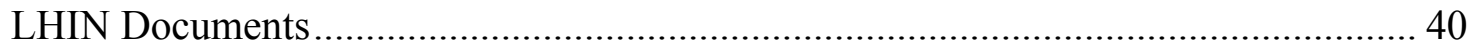

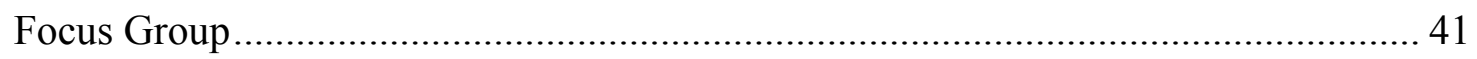

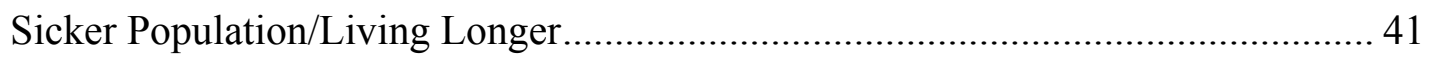

Caregiver Burden/Child Comfort Levels................................................................. 43

Communication with Service Providers/Parents ................................................... 45

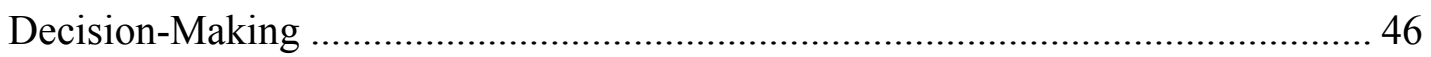

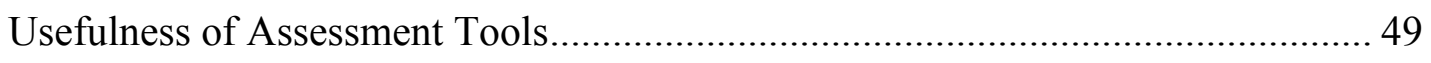

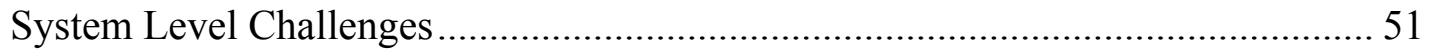

Lack of available services/health human resources .............................................. 52

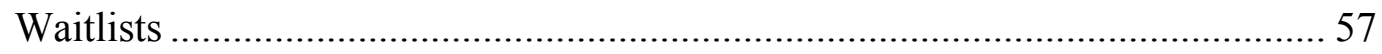

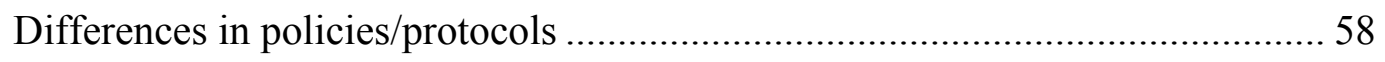

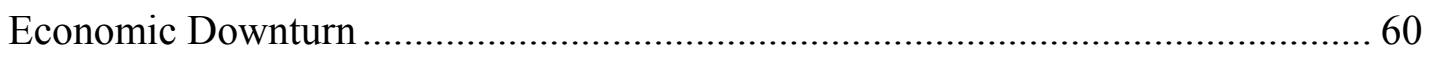

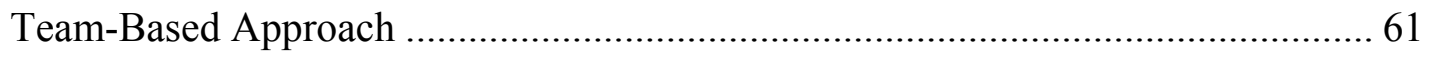

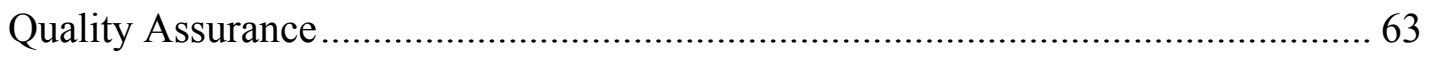

Changes Since the Implementation of the LHIN's ..................................................... 65 
Future Transformation of Home and Community Care Services .......................... 66

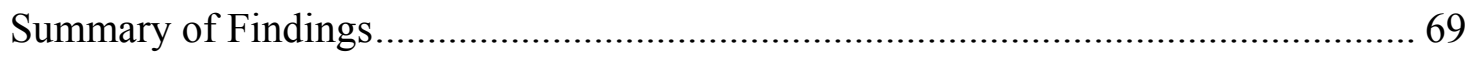

Chapter 5 - Discussion and Study Implications ................................................ 70

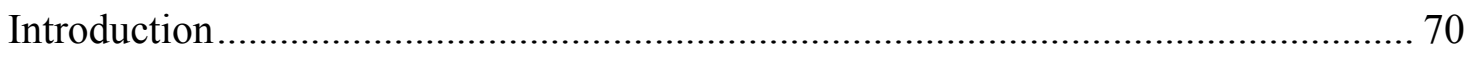

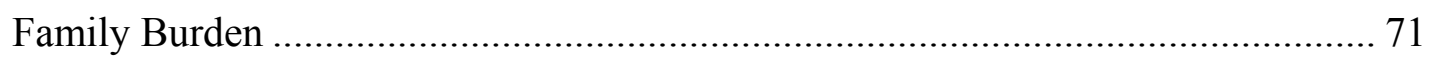

Health Human Resource Challenges ................................................................ 74

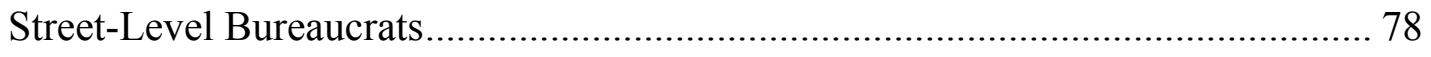

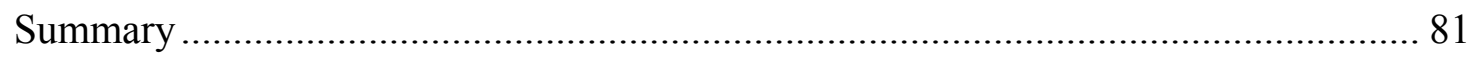

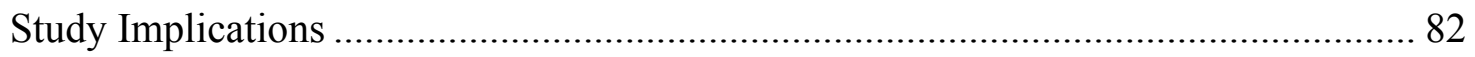

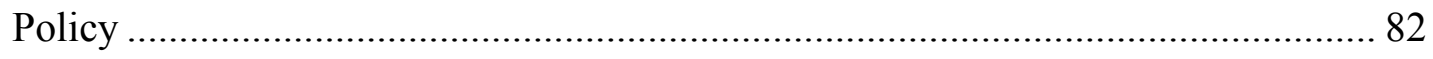

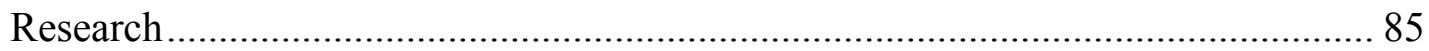

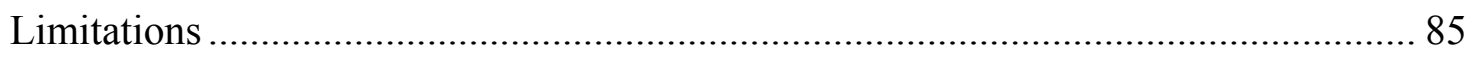

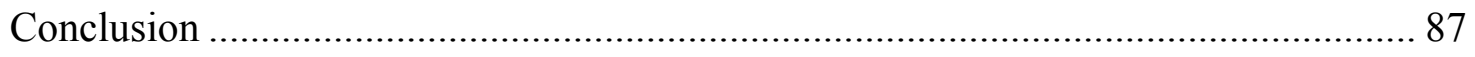

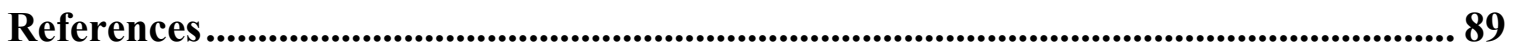




\section{List of Appendices}

Appendix A - Consent for Participation in Research ........................................................99 97

Appendix B - CCAC Case Manager Demographics ........................................................... 103

Appendix C - CCAC Case Manager Interview Guide .................................................. 104

Appendix D - Data Analysis: Development of Codes ....................................................... 106 


\section{Chapter 1 - Introduction}

\section{Background}

Throughout most of North America, there has been an exponential growth of medically complex and technologically dependent children (persons under the age of 21) living with their families in the home and community (Kirby, 2002; Romanko, 2005). Several key factors have contributed to this growth, namely improvements in assessing, diagnosing, and treating children's conditions (Spalding, Hayes, Williams, \& McKeever, 2002; Wong, 1991). Additionally, major advances in medical technology and pharmaceutical therapies mean that children who would have previously died from their conditions, now live longer with ongoing medical needs. Survival rates of infants have increased significantly in recent years due to improved medical care and knowledge, as well as improvements in hospital intensive care units, specifically in the area of neonatal care (Cohen, Friedman, Nicholas, Adams, \& Rosenbaum, 2008; Kirk, 2001; Newacheck \& Halfon, 1998; Newacheck, Strickland, Shonkoff, Perrin, McPherson, McManum, et al, 1998; Spalding, Hayes, Williams, \& McKeever, 2002).

Cohen, Friedman, Nicholas, Adams, and Rosenbaum (2008) highlight that currently there is no common definition in the literature for medically complex children but indicate that "this population can be understood conceptually as those children whose problems are multiple in terms of health and developmental needs, services, sectors of care, and locations of care" (p. 8). For the purposes of this study, this will be used as the conceptual definition for the population of medically complex children between 0 to 18 years of age. 
Over the past 10 to 15 years, much of the literature has shown that the demands for child and youth home care in Canada have been significantly increasing (Hayes, Hollander, Tan, \& Cloutier, 1997; Kirby, 2002; Spalding, 2005; Spalding, Hayes, Williams, \& McKeever, 2002). The Kirby Commission Report on health care in Canada estimated that children comprised up to $15 \%$ of all home care clientele (Kirby, 2002). Due to increases in survival rates, there has been a subsequent increase in the demand for paediatric home and community care services across all jurisdictions.

Due to technological advancements, pharmaceutical innovations, and increased diagnostic knowledge, there has been a societal expectation of saving an individual's life at all costs (Alexander, Rennick, Carnevale, and Davis, 2002; Carnevale, Alexander, Davis, Rennick, \& Troini, 2006). Therefore, medically complex children that have survived serious injury or illness now require ongoing health and medical care through the rest of their lives (Appierto et al., 2002; Edwards, O'Toole, \& Wallis, 2004; Spalding, 2005). As survival rates of medically complex children are increasing, many are living well into their adult years. As a result, hospitals and rehabilitation institutions are no longer able to provide care to this increased population of children for extended periods of time and therefore rely on home and community care resources to provide the necessary care. Parents are now providing complex medical care and procedures in the home setting, that would have until recently, only been provided by health care professionals in the hospital setting (Kirby, 2002; Kirk, 2002; Kuster, Badr, Chang, Wuerker, \& Benjamin, 2004; Romanko, 2005; Spalding, 2005; Spalding, Hayes, Williams, \& McKeever, 2002). 
The state of families with medically complex children who require home based care can be further complicated by their family structure. The Canadian Council on Social Development (CCSD) conducted a study, based on data obtained from the National Longitudinal Survey of Children and Youth, and found that $21 \%$ of children with special needs (i.e. requiring some home and community-based services) live in single-parent households. Single-parent families with medically complex children face significant difficulties as they must balance work and caring for their children even when services are unavailable. In many instances, the parent is forced to leave their job in order to care for their child. This has the potential to place the parent in a detrimental financial situation as they already have considerably high financial costs paying for special clothing, transportation, special diets, medications, home alterations, supplies and equipment (Roeher Institute, 2000). As an indication of how recently this community of medically complex children emerged, neither Statistics Canada nor the United States Census Bureau have collected any specific demographic data regarding these children.

Provincially, over the last several years, the health care system in Ontario underwent a major restructuring, with a stronger focus on providing professional health care services in the home and community environment (Baranek, Deber \& Williams, 2004; Hollander, 2001). In 2007, Ontario altered the funding structure for the majority of health care services with the implementation of 14 Local Health Integration Networks (LHINs) across the province.

This study is particularly well timed as it coincides with the implementation of the LHINs and the greater emphasis of providing health care in the home and community setting since the 1990s, the demand for home and community care services is rapidly 
growing (Baranek, Deber \& Williams, 2004; Spalding, 2005; Spalding, Hayes, Williams, $\&$ McKeever, 2002). The aim of this research is to explore and gain an understanding of the issues and challenges when assessing and allocating home and community care services to the medically complex child home and community care population. This research aims to add to the limited scholarly research that is conducted in the area of home and community care on medically complex children. Additionally, this research aims to inform policy makers at the local and provincial level as Ontario undergoes restructuring of health care delivery and funding, especially regarding the home and community care needs of medically complex children and their families.

\section{Statement of Study Purpose}

The purpose of this research is to explore and understand how Care Coordinators in a large urban home and community care centre assess, allocate, and manage home and community care services to families who are caring for medically complex care children in the home and community environment. 


\section{Chapter 2 - Policy Context and Literature Review}

This chapter consists of three sections. The first section discusses the relevant Canadian policy context and background as it relates to the population under study. The second section reviews the literature, highlighting three critical areas: 1) Prevalence of the population under study; 2) System issues and challenges; and 3) Family/caregiver demands. The third section discusses the framework utilized for the study.

\section{Policy Context}

The current state of health care in Canada has caused policy-makers and researchers to investigate the existing key issues and trends. The major factors that have pushed health care issues to the top of Federal, Provincial, and Territorial agendas are the governments' and public's concern over timely access to health care services, spending on health care, and the overall sustainability of the health care system. Several key documents highlighting the ongoing discussion regarding the sustainability of the Canadian health care system include: the Romanow Commission on the Future of Health Care in Canada (2002); the 2003 First Ministers' Accord on Health Care Renewal to which $\$ 34.8$ billion was committed over five years; and the 2004 Ten Year Plan to Strengthen Health Care where the federal government committed $\$ 41.3$ billion over 10 years.

These documents and reports identify several important areas as key issues across the health care system affecting the health of Canadians. These include: primary health care (i.e. sustain and expand on successful models of innovation and delivery); health human resources (i.e. educate additional health care workers or redefine roles in order to address critical shortages); access to community-based services (i.e. expand publicly 
funded services to the home/community setting); wait times (i.e. improving wait list management and timely access in key areas such as diagnostics, treatments, and surgery); and pharmaceutical management (i.e. catastrophic drug coverage). In the 2003 First Ministers' Accord on Health Care Renewal, a 5-year \$16 billion Health Reform Fund targeting primary health care, home care, and catastrophic drug coverage was established (Health Canada, 2003).

An indication of the importance of the shift in the site of care begins with an understanding of the Canada Health Act (CHA). The CHA is governed by five principles: comprehensiveness, portability, universality, accessibility, and public administration. It is these five principles that ensure all Canadians receive medically necessary health care (Health Canada, 2005). Under the CHA, every Canadian citizen, regardless of where they reside, has access to all medically necessary care (e.g. health care professional services, pharmaceuticals, in-patient hospital stays, diagnostic tests, etc.) provided within the hospital setting regardless of the ability to pay (Health Canada, 2005). Hospital care for all Canadian citizens is a universal entitlement under the conditions of the CHA. However, once an individual leaves the hospital and enters the community, care falls outside of the CHA. Therefore, individuals are no longer guaranteed services, even those services considered medically necessary or that would have been provided to them within the hospital setting (Baranek, Deber \& Williams, 2004; Spalding, 2005; Williams, Deber, Baranek, \& Gildiner, 2001).

The Federal Government supports funding for professional health care services that are provided outside of the hospital setting, but does not dictate how these funds are to be allocated and which services to provide. Therefore, home and community care 
services that are publicly funded fall under provincial jurisdiction. Each province has the discretionary right to decide which home and community care services, if any, will be publicly funded. Since some home and community services and programs are publicly funded, they can be viewed as an additional health care benefit within each province, resulting in great variation of available resources between provinces (Salib, 2007; Spalding, 2005; Williams, Deber, Baranek, \& Gildiner, 2001).

In Ontario, the location of the current study, eligibility for available professional home and community services is determined upon an assessment by a Care Coordinator who works for one of the 14 Community Care Access Centres (CCAC) across the province. The Ontario Government mandates the CCACs to provide home and community services to all Ontarians and are governed under the Ministry of Health and Long-Term Care (MOHLTC). The CCAC indicates their mission is "to deliver a seamless experience through the health system for people in our diverse communities, providing equitable access, individualized care coordination and quality health care." (Community Care Access Centre, 2010). The CCACs offer Ontarians an access point to professional home and community services. These services include: nurses, personal support workers, nutritionists, occupational and physiotherapists, social workers, palliative care monitoring, as well as supplying medically necessary equipment such as numerous assistive devices in the home. These services are intended to support the wellbeing, quality of life, and independence of Ontarians, allowing them to remain in their homes for as long as possible. To accomplish this, the CCAC Care Coordinators assess individuals to identify their care needs and appropriate resources that will allow them to remain in their own homes. The CCAC Care Coordinators are all registered health care 
professionals and include registered nurses, social workers, occupational therapists, and physiotherapists. Once individuals are assessed, the Care Coordinators are responsible for the allocation, implementation, coordination, and management of professional services and possible referral or consultation for alternative community resources. The CCAC Care Coordinators do not provide direct treatment to individuals, but maintain binding contracts with multiple professional home and community care organizations.

When medically complex children are discharged from institutional care settings, they are considered to be in stable medical condition, but still have ongoing health care needs that can be met within the home and community setting. These children are now dependent on families, formal and informal caregivers, and various community support services to provide them with the necessary health and medical care they require (Kuster, Badr, Chang, Wuerker, \& Benjamin, 2004; Romanko, 2005; Spalding, Hayes, Williams, $\&$ McKeever, 2002; Toronto District Health Council, 2000). Of significant importance, with the growing population of medically complex children requiring home care, are the parents and families caring for these children when they are discharged from the hospital. It is not uncommon that the parents are left responsible for coordinating numerous services and providing a significant amount of care for their child after being discharged home, even care considered medically complex, with very limited community support services (e.g. professional paediatric nursing care, respite services, or financial supports). Of importance to this research is understanding that the decision-making regarding the allocation of home and community care services to individuals devolves down to the CCAC Care Coordinator's level. Therefore the Care Coordinators can be viewed as the 
'gatekeeper' or 'street-level bureaucrat' to accessing publicly funded services (Hayes et al., 1997; Kirk, 1998; Spalding, 2005; Williams, Deber, Baranek, \& Gildiner, 2001).

Although the literature has discussed the importance of investing in effective home care, particularly around families with medically complex children, this population continues to be overlooked. Other than the Kirby (2002) statement that children comprise approximately $15 \%$ of the home care population, neither The Kirby Report (2002) nor Romanow Commission (2002) acknowledge children as a distinct and unique home care population. While the Kirby Report (2002) and Romanow Commission (2002) support the investment into home care, these reports primarily discuss the acute care population, disregarding the long-term chronic care population who will rely on home care services for their entire lives due to their illness or disability. Unfortunately, since the Kirby Report (2002) and Romanow Commission (2002) discuss services confined to the CHA legislation.

\section{Literature Review}

There are several research studies focusing on the needs of medically complex children originating out of the United Kingdom, the United States, and Canada that will be reviewed in the following section. The majority of these studies focus on three main areas. First, these studies address the increasing prevalence of the medically complex child population in the home and community care setting. They focus on how advances in medical technologies have enabled medically complex children to live longer and fuller lives, therefore enabling the transition from the acute care setting to the home and community care setting. Second, as a result of the increased population, the studies to date have focused on the demands placed on the health care system and the inherent 
challenges in providing care in the home and community care setting. Last, the literature addresses the various parental stressors and demands such as financial burden, need for respite and the loss of social networks, and their overall impact on the quality of life of the child and family when care has been transferred into the home and community care setting.

\section{Prevalence of Population}

There currently remains a limited body of research with regard to the increased prevalence of the medically complex child population. Much of the current research attributes the increase to improvements in medical technologies, diagnostics, and an increase in public awareness. Nevertheless, the literature does not provide complete information regarding actual numbers of medically complex children, as well as the health care services they utilize.

In 2003, the Participation and Activity Limitation Survey (PALS) indicated that nearly $23 \%$ of families received help from friends, neighbours, other family members, and privately paid individuals in addition to the publicly funded services they had already been receiving (Statistics Canada, 2003). The PALS (2003) study indicated that in 2001, 26,000 children between 0 to 4 years of age and 155,000 children between the ages of 5 and 14 years living in Canadian households had a disability (Statistics Canada, 2003). Additionally, PALS identified that approximately 118,000 children (65\% of children with disabilities) between the ages of 0 and 14 have a disability composed of one or more chronic conditions, which include such chronic conditions as asthma, kidney disease, and heart conditions or suffering from conditions such as attention deficit disorder, autism, or 
cerebral palsy. The PALS (2003) study is a good indication of the extent of this population within the Canadian context.

Wise (2004) highlights the data from the National Health Interview Survey (NHIS) which sampled approximately 40,000 households, representing 30,000 to 40,000 children. The NHIS acknowledges the increased prevalence of children with chronic illnesses over the past several decades. The NHIS data indicates that approximately $15 \%$ of all children have a chronic illness, with nearly $33 \%$ of those children having moderate to severe conditions. Wise (2004) reports that between 1962 and 2000, hospital admissions to paediatric care institutions due to chronic conditions rose from $25 \%$ to 55\%. Additionally, Wise (2004) highlights that in 1962, children who were admitted two or more times that year accounted for only 4\% of hospital bed days; in 2000 these children accounted for approximately $25 \%$. In terms of utilization of health care resources, Wise (2004) indicates that these children have three times more physician contacts responsible for their medical needs and eight times more days in hospital.

Kuster et al. (2004) demonstrate in their study that technological advancements have now created a community of medically complex children residing outside of institutional care who are dependent on medical technology, such as ventilators, as well as potentially requiring medically complex care on a daily basis. This is especially significant due to the fact that once these children are discharged back to their homes, the responsibility for care shifts to the parents. Without the appropriate home and community support services, families are left alone and untrained to care for their medically complex child, resulting in increased levels of stress, abandonment, and burden, which can potentially compromise the health of individuals involved. 
Additionally, this may result in an inability for the parents to care for their own health due to time constraints which prevent them from engaging in healthy behaviours such as exercise, sleep, and good nutrition (Kuster et al., 2004). This shift in the site of where care is provided has far reaching implications on the care and quality of life for the child and their family members.

\section{System Issues and Challenges}

With the increased prevalence of the medically complex child population, the literature highlights an increased awareness of the pressures on acute care institutions. These pressures are related to the multiple and extended hospitalizations, shortages and cut backs of acute care beds, as well as shortages of health care professionals in the home and community setting.

Kirk (1999) investigated the challenges that families caring for children with complex health care needs face and how health care professionals can develop services to support these families. Additionally, she emphasizes through her research the inherent difficulties for parents and professionals when shifting the care of a medically complex child from the hospital to the community. Qualitative interviews were conducted with parents of 24 technology-dependent children, as well as interviews with four technology dependent children. Many of the children in the study had intensive care needs, some needing 24-hour care or supervision, placing significant pressures on the parents. Many of the parents had undergone significant training in order to care for their child, therefore many did not feel comfortable leaving their child to other family members or friends and were left reliant on the arrival of professionals to take a break from their care responsibilities. Kirk (1999) found that among the families, funding arrangements 
differed significantly, ranging from a few hours per week to receiving 24 hour care, as well as care being provided by individuals ranging from professional nurses to support workers. Most importantly, Kirk (1999) found that funding and support received by families did not correlate with the level or type of care the families required.

Ray's (2005) Canadian study examines the barriers parents of medically complex children face when forced to organize community-based services for their child. The study consisted of 34 children, between the age of 1.5 to 16 years of age who had one or more chronic health conditions. These children had a variety of care needs ranging from use of mobility aids to 24-hour ventilator support. Her findings indicate that the child's diagnosis was not predictive of the services they received, as it was dependent on the knowledge of the professionals assessing the child. Ray (2005) suggests four principles to guide health policy development to effectively provide services to this high needs population. The first principle recommends integrating all levels of services, as families are faced with multiple levels of ministries (i.e. federal/ provincial/ local) with differing funding, service criteria, and qualifications, resulting in significant fragmentation. Second is the need for more of a proactive rather than a reactive approach to planning for children living in the home and community.

Ray (2005) emphasizes the current system allocates services on a needs-based approach focusing on the deficits of the family to manage or cope independently. Through proactive planning at predicable key transition periods such as starting school, transferring from one school to another, and transitioning into adult services program can greatly aid in the family's ability to manage the care for their child. Additionally, informing the families about these key stages and the changes they should expect will 
save them time and effort in locating services. Third is the need for flexibility in planning services to meet the unique needs of the family. Many families reported instances where services and programs failed to meet their needs, requiring the parents to adjust their schedules to ensure their child receives any services. Additionally, families not only requested flexibility in terms of when services are delivered but also what services are delivered, through a service program that is collaboratively created by the family and professional. Lastly, families expressed a desire for a fair allocation of resources and accountability to information, eligibility criteria, and processes for decision-making.

Two recent systematic reviews highlight the challenges in gathering research and evidence in the field of paediatric home and community care. First, a Cochrane Systematic review focused on the cost-effectiveness and reduction of hospital admissions and length of hospital stays when clients receive specialized paediatric home and community care services. Cooper et al. (2006) examined 1655 titles, yielding only 5 randomized controlled trials (RCTs). The five RCTs of children 0 to 18 years of age with acute and/or chronic illnesses allocated to specialist home-based nursing services were compared with conventional medical care. Outcomes studied included: the utilization of health care services, physical and mental health, satisfaction, adverse health outcomes, and costs. The results of the individual RCTs showed improved satisfaction with homebased care with no adverse impact on physical health outcomes for children. However, there was no evidence suggesting that having specialized home-based nursing services in place reduced their ability to access hospital services or lead to decreased lengths of stay 
when hospitalized. They indicate that further trials are needed in the areas of: measuring health, satisfaction, service utilization, and long-term cost evaluation.

The second review, by Parker et al., (2006) examines the costs and effectiveness of paediatric home care and focuses on service usage, clinical outcomes, costs, and overall impact on the family. Populations of interest include medically fragile infants, technology dependent children, children with mental health issues, and those receiving generic child/youth home care. Their review utilized 20 electronic and other sources, identifying 1730 relevant records with only 10 studies being RCTs. Parker et al. (2006) indicate that there are limited RCTs measuring the psychological and/or financial impacts of families caring for medically fragile children in the home setting. This is of significant importance as the literature indicates that fragile babies require substantial emotional and financial support over the long-term. Therefore, Parker et al. (2006) recommend conducting an RCT to highlight the supports required by the family, the ultimate benefits in providing these supports to the family, and at what cost. Parker et al. (2006) acknowledge the rapid growth in research in the area of paediatric home care and indicate the possible need for alternative research methods (not just RCT). Such studies would address key questions related to the practical and ethical aspects of support that can be effectively delivered to these children and families in the home setting, even if it is more cost effective to the health care system.

Rosenbaum (2008) utilized an expert panel to help devise an approach to effectively address the challenges in coordinating care for medically complex children within the Canadian context, as there were very few studies that have focused on the mechanisms, approaches, and evaluations of care coordination. The expert panel 
acknowledged that the current home and community care system in Ontario does not support a seamless transition from the hospital to the home and community setting. The disparities of not having a seamless and integrated system include suboptimal health outcomes for the medically complex child, dissatisfaction with the health care system by the child and family, and frustration from health care professionals. These disparities often lead to a compromised quality of life for the child and family, as well as an inefficient use of health care planning, resources, and spending.

The expert panel addressed three major themes that are separate and unique but are all interrelated. These major themes were: 1) collaboration; 2) health human resources; and 3) transitions. Each of these themes was determined to be 'essential' to successfully coordinating services for this population. The theme of collaboration was comprised of two important elements: inter-professional care and communication. Families and caregivers who care for a medically complex child typically have multiple health care professionals such as physicians, nurse practitioners, social workers, dieticians, and possibly respiratory therapists following the health care needs of the child. To ensure effective care, the various recommendations and treatments provided by each of these professionals need to be communicated to one another in order to eliminate errors and redundancy and for treatments to be complementary. Ultimately, Rosenbaum (2008) suggests that, "to ensure appropriate and effective care, and to avoid fragmentation of care among the various providers and care settings, all care providers will have to collaborate in the planning and delivery of care and services for this population" (pg. 23). 
The theme of health human resources identified by the expert panel is an issue that needs to be addressed within the home and community setting. The expert panel particularly identified that due to the medical complexity and fragility of these children, health care practitioners in the community hesitate to take on medical responsibility. Additionally, the expert panel highlighted that the remuneration and funding system does not support practitioners to take on these specialized and high needs children.

Lastly, the expert panel highlighted the importance of what they called "transitioning". Medically complex children undergo multiple transitions as they enter new life stages, between health care settings and schools, as well as receiving services from several providers. Each of these transitions has the potential to cause a significant disruption to the continuity of care the medically complex child requires. A particularly critical transition phase that the expert panel identified occurs when medically complex children are transitioned from paediatric to adult health care services within both the acute care setting and the home and community care setting. To address the inherent transitional issues and barriers, the expert panel suggests the creation of transitional programs for children and youth between the ages of 16 and 25 and indicates the importance of care coordination for all medically complex children and their families.

\section{Family/Caregiver Demands}

The literature discusses significant demands placed on the family and child in the shift from the institutionalized care setting to the community care setting. Once home, families/caregivers must provide care that is often new and complex, within an environment that is not conducive to providing such care, and all of which extend beyond the typical nurturing care responsibilities of a parent. Two critical factors that many 
families face when caring for a medically complex child in the home are the financial stressors and potential for social isolation (Carnevale, Alexander, Davis, Rennick, \& Troini, 2006; Kirk, 1998; Perrin, et al., 2007; Wong, 1991).

Studies have shown that financial stress is often due to one of the parents having to leave their paid employment in order to care for their medically complex child (Perrin, et al., 2007; Wong, 1991). The level of financial stress is compounded for low income families and/or single parent families (Beresford, 1996; Ellis et al., 2002). Bremberg (2002) highlights a direct correlation between the parental stress and the child's health and well-being. As parents face increased levels of stress, they are unable to effectively adjust and the child's health and well-being can subsequently decrease. Additionally, many parents report feeling socially isolated in their homes (Gough et al., 1993; Kirk, 1998; Taanila et al., 2002; White \& Hastings, 2004). Often times, parents fear leaving their child alone in the care of others for an extended period of time and therefore do not take this time for themselves. It has been shown that providing financial support and respite opportunities to these families can considerably help decrease the level of stress and increase the quality of life for these individuals, giving them an opportunity to cope (Quine \& Pahl, 1991; Schilling et al., 1984; Wallander et al., 1989).

Yantzi, Rosenberg, and McKeever (2007) effectively demonstrate the challenges regarding feelings of isolation that mothers of medically complex, long-term care children face on a daily basis and how the current funding and delivery of home care services specifically related to providing respite care is not sufficient to address the needs of families. Although, children's quality of life and life expectancies have increased due to the advances in medical technologies that allow them to be cared for in the home 
environment, the time and physical and emotional demands of care routines can have detrimental effects on the family unit. Yantzi, Rosenberg, and McKeever (2007), studied the direct and indirect consequences for families who are the primary caregiver for technologically dependent, medically complex care children receiving home care services such as nursing care, physiotherapy, occupational therapy, and home support. The study utilized semi-structured interviews and data analysis of the mother's experience and was guided by grounded theory. The study sample consisted of eleven mothers of medically complex long-term care children residing in Ontario who were receiving publicly funded home care services for at least six months. The children had compromised activities of daily living status, and the child's condition was stable and well managed. One of the major consequences that families experienced was isolation, as many caregivers feel trapped in their homes resulting in limited social interactions with others. The extraordinary work required to care for children with chronic illnesses or disabilities is often physically, mentally, and emotionally taxing, and requires considerable skill, knowledge, and responsibility on the part of mothers (Yantzi, Rosenberg, \& McKeever, 2007). These authors also show how mothers caring for children with long-term care needs experienced isolation and social disconnectedness.

Sherman (1995) utilized a pre-test, post-test design to determine the impact of respite services on family stress and quality of life. Interviews occurred at the onset of the study and six months post participation in the study. The measurement tools employed in the study included 'The Impact on Family Scale' and 'The Brief Symptom Inventory'. The Impact on Family Scale measures financial, family, personal, and sibling strain on a 4-point Likert scale. The Brief Symptom Inventory required participants to 
answer questions regarding their current state of anxiety, depression, and somatization, also utilizing a 4-point Likert scale as a form of measurement. The study sample included 73 families who met the following eligibility requirements: 1) an identified poor support network, 2) a child with a medically complex illness who was younger than 21 years of age; and 3) the family currently received fewer than five days of respite services per week. A means of control in order to assess for the impact of respite services an individual family receives, Sherman (1995) determined what the treatment rate (i.e. respite care services) was for each family. The treatment rate was computed by number of months of participation within the program by the number of respite visits received.

Post-test data were collected from 26 families, yielding a response rate of approximately $36 \%$, thus the attrition rate was significantly high. The data collected indicated that families caring for chronically ill children want respite care services, and that higher utilization rates of respite care services correlated to lower sibling strain $(\mathrm{p}<$ $0.02)$, lower expressed somatization $(\mathrm{p}<0.05)$, and a decreasing rate of rehospitalizations $(\mathrm{p}<0.07)$. Upon completion of the study, many of these families expressed a need for more hours of respite care than was provided by the program, indicating that respite care is a vital component to providing effective home-based care for chronically ill children.

Heaton, Noyes, Sloper, and Shah (2005) studied families in the United Kingdom who were caring for technologically dependent children within the home environment. The researchers were interested in investigating the experiences of these families with respect to how caring for technologically dependent children affected their natural daily routines and practices. Technologically dependent devices included ventilators, feed 
pumps, intravenous drug therapies, oxygen therapy, and home dialysis machines. Study participants included 36 families ( 75 participants), whose children were 18 years of age or younger, living at home, and dependent on one or more technological device. The researchers obtained information from parents, siblings, and the technologically dependent child through face-to-face, semi-structured interviews lasting between one and two hours.

The researchers report that the demands of caring for their technologicallydependent child led to some negative effects such as limited attendance at school, limited opportunity for future employment, and an overall limited social life, combined with the family's inability to connect with other social networks (Heaton, Noyes, Sloper, \& Shah, 2005). For example, because some of the medical equipment required supervision during the night, many parents consistently suffered sleep disruptions. These physical, emotional, and time demands ultimately contributed to the social isolation and exclusion. Heaton, Noyes, Sloper, and Shah (2005) also identified that in the United Kingdom, the home and community care health care system provides insufficient respite care, especially during the evenings and throughout the night, thus not allowing parents to have a less stressful night's sleep. They also concluded that further research is required to develop service plans or models that effectively reduce or alleviate the time demands on families who care for technologically dependent children.

In addition, a large number of families have more than one child, therefore parents are managing care for a child with complex care needs in addition to caring for the siblings. While caring for their medically complex child, parents must simultaneously care for other family members. Spalding, Hayes, Williams, and McKeever (2002) found 
that the families' homes are not adequately adapted to appropriately take care of children with complex care needs (i.e. wheelchair accessibility and room for medical devices) and there are limited resources available to assist families to make the required home renovations. In addition, Spalding, Hayes, Williams, \& McKeever (2002), also found that families may be subjected to an increased level of stress because of their new role as primary caregiver for a medically complex child, which may lead to an inability to cope with their new family life. Adding to the caregiver's stress is the understanding that their medically complex child may require specialized services for his/her entire life.

\section{Summary of Literature}

The literature indicates medically complex children and their families may experience a higher quality of life within the home and community setting as opposed to remaining in institutionalized care, when the option is available. However, the literature highlights that the child and family could experience several potential barriers for a successful transition from the institutional care setting to the home and community care setting, when home and community care services do not adequately meet the needs of the child and family. These include an increased difficulty in maintaining a high quality of life and well-being for all individuals involved, increased occurrences of stress and breakdowns, social isolation due to caring for the child when services are not available, a lack of required respite services for parents and caregivers, and an increased financial burden for the family due to increased privately paid health care costs, and lost household incomes (Hayes \& McElheran, 2002; McKeever, 1994; Ray, 2005; Snowdon \& Kane, 1995; Ward-Griffin \& McKeever, 2000). 
Many studies highlight the high burden placed on families because of the complexity of care that these children require. These families have been shown to demonstrate short-term stressors which typically revolve around the discharge from the acute care setting back into the home and community setting as families are potentially dealing with new demands and responsibilities which they might not feel capable or qualified to do. Longer term stressors for families include the potential challenges in securing a daycare facility and/or school that will support and accommodate the additional care needs their child may require. Additionally, families typically face a financial burden and stress due to one family member leaving their job in order to manage the care needs of their child. The literature indicates that families experiencing these stressors are known to suffer from physical and mental health issues.

Due to the highly specialized needs of the medically complex child population, there is an associated high burden on the health care system. Many of these children are frequent users of the health care system, both the acute health care as well as home and community health care services. This is due to the complexity of their medical condition, limited specialized resources in the community, and discomfort or fear from providers to supply or manage their medical care needs.

It has been identified throughout the literature that there is also a lack of research in the area of care coordination for the medically complex child home and community care population. Although managing individuals within the home and community setting is not a particularly new phenomenon, managing this particular population in the home and community settings is a fairly recent development. While much of the literature identifies the growth of this population and the multiple factors contributing to their 
growth, there are limited studies focusing on the importance of care coordination.

It is apparent that understanding and possessing the knowledge concerning the medically complex child home care population is imperative for those who are responsible for assessing, allocating, and managing home care services. To date there has been a lack of literature investigating how those who are responsible for care coordination of home and community care services take into consideration family needs when allocating services. The opportunity to care for the medically complex child in the home setting has the potential to increase the quality of life of all individuals involved, however, in order to be effective, these clients need to be properly assessed and the home care services they require need to be appropriately allocated and delivered.

\section{Framework for Study}

Street-level bureaucracy is the framework chosen to understand how Care Coordinators at a large urban home and community care centre assess, allocate, and manage home and community care services for families who are currently caring for medically complex children within the home and community. For the purposes of this research, assessment includes the processes undertaken by Care Coordinators when conducting an initial assessment of the medically complex child and their family, as well as any additional follow-up assessments (if necessary) or assessments for other programs/organizations. Allocation refers to the methods or mechanisms by which the Care Coordinators decide how to interpret their assessment findings and allocate home and community health care resources. Management refers to the daily activities of the Care Coordinators. 
Lipsky (1980) describes street-level bureaucrats as, "public service workers who interact directly with citizens in the course of their jobs, and who have substantial discretion in the execution of their work" (p. 3). Additionally, Lipsky (1980) highlights that many of these public service workers are faced with conflicting dilemmas as they attempt to fulfill the demands from their organization, which often conflict with the demands of their clients. Lipsky (1980) outlines three reasons why decisions are made at the discretion of street-level bureaucrats. First, many of the situations street-level bureaucrats are involved in are complicated and multi-faceted, and thus difficult to condense into a prescribed format. Second, street-level bureaucrats are placed in situations that require an analysis and response to the human dimensions of the situation. Third, the street-level bureaucrats' discretion allows clients to believe in them as the gatekeeper to their well-being, contributing to the legitimacy of the welfare state. Ellis, Davis and Rummery (1999) state that, "street-level bureaucrats behaved defensively in order to cope with the pressures of high levels of demand coupled with the chronic shortfall in resources" (p. 264). This is an important aspect for this study, as Care Coordinators can be viewed as the gatekeepers to home and community care services, as they are the individuals who assess, allocate, and manage the delivery of publicly funded services provided to the children and their families. The Care Coordinator's decisions have a crucial impact on the allocation of resources to individuals. Therefore, utilizing street-level bureaucracy as a theoretical lens for this study will enable the researcher to critically analyze issues and/or trends faced by Care Coordinators. 
Currently, there is no standardized assessment tool to assess children for home and community care services, unlike the adult and senior populations, which utilize such tools as the International Resident Assessment Instrument (interRAI). The internationally utilized interRAI assessment tool is a comprehensive tool which aids in the decision-making process with the creation of care plans and care plan implementation through the use of clinical assessment protocols, followed by evaluation measures but, the interRAI does not determine the allocation of resources (interRAI, 2008). As a result, Care Coordinators independently assess medically complex children for publicly funded home and community care services, and have the discretionary power to allocate home and community care services. Therefore, the CCAC Care Coordinators can be viewed as street-level bureaucrats, as they determine who will receive services and which services will be allocated to a client. In Ontario, it is these CCACs that act as the access point for Ontarians to be assessed to receive home and community care services.

\section{Summary}

Across Ontario and much of the developed nations, there is an increasing demand for home and community care services for medically complex children. Although there is an awareness of the demands of this population, the literature highlights the numerous challenges faced in meeting their needs such as the lack of specialized health care providers, the poor transitioning from acute care to home care, and multiple ministries and service agencies involved in the care. The studies to date continue to focus on the issues and challenges of delivering home and community care services, but rarely do they discuss the assessment and allocation of home and community care services by Care Coordinators for this particular population. Therefore, this study utilizes the framework 
of street-level bureaucracy to understand the processes by which Care Coordinators assess and allocate home and community care services to children with medically complex care needs. 


\section{Chapter 3 - Methodology and Procedures}

This chapter provides details of the research design and methods utilized in this study, highlighting each of the steps in the process of data collection and the analyses undertaken to address the research question.

\section{Research Design}

\section{Qualitative Design}

The study methodology chosen to conduct this research is qualitative inquiry and design. Qualitative inquiry is pertinent to this study, as there are currently gaps in the research regarding care coordination of this population. Denzin and Lincoln (2005), describe qualitative research as a, “...situated activity that locates the observer in the world" (p. 5). This is accomplished by the researcher through "...studying things in their natural settings, attempting to make sense of, or interpret, phenomena in terms of the meanings people bring to them" (Denzin \& Lincoln, 2005, p. 5). Qualitative research allows the researcher to view the phenomenon from multiple angles, imposing little or no assumptions on the phenomenon in order to remain open and unbiased. The choice of qualitative research stemmed from the desire to gain a detailed understanding of the Care Coordinators' perspectives on the process of assessing, allocating, and managing services to families caring for medically complex children in the home and community setting. Utilizing this methodological design allowed the researcher to gain, through direct conversation with the Care Coordinators, a detailed understanding of the phenomenon that one may not find or read in the literature. 


\section{Case-Study Approach}

A case-study approach was employed to capture, explore, and understand the experiences of Care Coordinators in assessing, allocating, and managing services to families caring for medically complex children. Case-study research is a qualitative approach allowing the researcher to explore a specific case or multiple cases through the collection of various forms of data, such as observations, interviews, documents, and reports (Creswell, 2007). Additionally, Yin (1994) describes case-study research as an inquiry that, "investigates a contemporary phenomenon within its real-life context, especially when the boundaries between phenomenon and context are not clearly evident." (p. 13). Stake (2005) expands on the notion of an investigator, indicating that the case-study researcher can be described as a writer or even biographer for an individual, highlighting a particular event or segment during their life. To gather pertinent data, case studies utilize 'how' and 'why' questions for the explanation of significant events, drawing on multiple data collection methods (Yin, 1994). Yin (1994) indicates that multiple data methods would include gathering information through direct observations, archival records, participant observations, interviews, and documentation analysis.

This qualitative study utilized a single case-study design with multiple units of analysis. The case-study methodology allows for the analysis of the intertwining complexity of the phenomenon in relation to its context. Due to the nature of the phenomenon, the researcher was unable to create different groups (i.e. experimental group and control group), manipulate variables, or control the context of the study. In order to understand the experiences of research participants and capture and explore the 
multiple views of the participants, especially when conducting a case study, data collection through interviewing is optimal (Stake, 1995). Yin (1994) also stresses the use of direct conversation as one of the most important data collection techniques when conducting a case study. Direct conversation creates an opportunity for the participants to state their views in an open forum environment with no negative outside repercussions

for their statements. Lastly, the case-study approach enabled the researcher to capture the feelings, interpretative views, and perceptions from the participant that cannot be captured by any other data collection method (Yin, 1994).

With case-study design, Yin (1994) suggests that direct conversations with participants should be open-ended and semi-structured. For this research, open-ended, semi-structured questions were utilized in the focus groups, allowing participants an opportunity to elaborate on any key issues or events they deemed necessary. Additionally, having an open-ended and semi-structured question format allowed the researcher to adapt their questions and investigate any issue or situation further, and react to any new issues that may be uncovered (Yin, 1994).

\section{Focus Groups}

For this research study, in order to capture the desired understanding of this population from the Care Coordinators perspectives, a focus group was conducted by the researcher. The utilization of a focus group as the method of gaining qualitative data has several advantages. Morgan (1993) contends that focus groups are effective at highlighting, understanding, and ultimately bridging any gaps that may exist between participants, through communal discussion regarding their knowledge and awareness of the issue or population under study. Focus groups are a method which utilizes a group 
interview, benefiting from the combined communication of the group members and the shared interactions among members to generate data in a relatively short period of time. Krueger and Casey (2009) indicate that focus groups promote direct interactions between multiple participants and the researcher, allowing for clarification regarding responses that were unclear and additional probing to extend or enhance dialogue. Additionally, proponents of focus groups highlight that due to the nature of shared conversation and interactions, individuals' opinions may change and develop as group discussion progresses. Krueger and Casey (2009) state that "focus groups work when participants feel comfortable, respected and free to give their opinion without being judged. The intent of the focus group is to promote self-disclosure among participants" (pg. 4). Ultimately, during the focus group, the researcher is able to "gain insights into both the range of opinions they have and the sets of circumstances that will lead to one response rather than another." (Morgan, 1993, pg. 18).

In order to capture sufficient data and capitalize on group interactions, the focus group should range from 6 to 12 participants (Krueger \& Casey, 2009). It is recommended that groups less than five participants should be avoided as they may not produce adequate participant interactions. Groups of more than 12 are also disadvantageous to the researcher as groups this large can inhibit the participants from articulating their experiences, potentially resulting in selective partitioning. For this research a focus group with seven Care Coordinators took place.

The sampling process is generally purposive, as participants are chosen to represent a range of the population under study. Additionally, purposive sampling attempts to test a specific hypothesis, rather than be representative of the general 
population. The participants for this research were purposively selected individuals possessing knowledge and experience in assessing, allocating, and managing home and community care services to medically complex children.

\section{Sample}

The target population for this research were the CCAC Care Coordinators who are, as indicated earlier, responsible for assessing, allocating, and managing home and community care services to children, families, and parents/caregivers living in the Greater Toronto Region. Of particular importance are those Care Coordinators who are currently managing children who have been diagnosed with a medically complex condition. These children and their families are receiving professional home and community care services such as nursing care, physician services, palliative care, rehabilitation services, and school health support that are assessed, allocated, and managed by the CCAC Care Coordinators.

\section{Sampling Method}

This research study utilized a purposive sampling approach. Researchers utilize the technique of purposive sampling of participants when they seek specific individuals or sites to study (Creswell, 2007). Additionally, Stake (1995) indicates that effective case studies maximize the experiences garnered from participants, which are achieved through the use of purposive sampling. Factors that could potentially hinder recruitment of participants include, but are not limited to, the availability of participants, length of time required for data collection with each participant, and the complexity of data requested from participants. 
Study participants were Care Coordinators working for a CCAC who are responsible for the assessment, allocation, and management of services for children with medically complex conditions. Children with medically complex conditions were defined as: a) individuals between the ages of 0 to 18 years; b) living in the home; c) diagnosed with a long-term medically complex illness, and d) require the administration of medications and/or therapies requiring a health care professional to provide care.

\section{Research Question}

In order to examine the assessment, allocation, and management of home and community care services for medically complex children by CCAC Care Coordinators, the following research question guided this study: "What are the experiences and decision-making processes of Care Coordinators in assessing, allocating, and managing home and community care services for children?"

\section{Data Collection Procedures}

\section{Documents}

To determine the policy perspectives and initiatives within the Ontario context regarding home and community services, public documents from the 14 LHINs across the province were sought. Specifically, to gain an understanding of the priorities placed on medically complex children within the home and community setting, Integrated Health Service Plans (IHSPs) were obtained from each of the 14 LHINs. Prior to the inception of the LHINs in 2007, each LHIN released IHSPs. These IHSPs outlined the specific target populations and those of greatest health care need in their specific LHIN, and described how health care dollars would be spent. 


\section{Focus Group}

Invitations to participate in a focus group occurred at a monthly Care Coordinator meeting. With permission from the manager, a short 15-minute presentation was given to all 15 Care Coordinators who manage and allocate home and community services for children with long-term care needs. Consent forms (Appendix A) highlighting the nature of the project and expectations of participants were handed out. Self-addressed, stamped envelopes were provided with the consent forms. A total of eight Care Coordinators consented to participate in the focus group. Feedback from the Care Coordinators who consented to participate indicated a preference to conduct the focus group two hours prior to their monthly Care Coordinator meeting at the regional office.

On the day of the focus group, one Care Coordinator was unable to attend as one of the clients on her caseload required an urgent home visit, therefore the focus group was conducted with seven Care Coordinators. Before starting the focus group, each Care Coordinator completed a voluntary demographics form (Appendix B). Written consent was obtained from all Care Coordinators before starting the focus group. The Care Coordinator focus group began with an introduction from the researcher and a short discussion regarding the purpose and rationale of the study. Prior to conducting the Care Coordinator focus group discussion an interview guide was created (Appendix C).

\section{Setting.}

The Care Coordinator focus group discussion took place at a mutually agreeable location for all Care Coordinators and the researcher. This decision was based on minimizing the burden on the participants to partake in the study. The focus group took place in a private room in which all participants felt comfortable discussing the research 
study questions. The time commitment of the Care Coordinators to complete the focus group was 88 minutes.

\section{Participants.}

The demographic forms completed by the Care Coordinators indicated that the participants were all licensed health care professionals with a wide range of professional experiences. Five out of the seven Care Coordinators had previous professional experience working directly with children prior to their current position. The number of years the Care Coordinators had worked in the home and community care setting ranged from 5 to 19. They had been in their current position from 2 to 11 years. As will be discussed below, the Care Coordinators are responsible for managing their own individual caseload of clients. The Care Coordinators in the focus group were asked to indicate the "average number of clients on their caseload". Depending on the specific geographical catchment area of the Care Coordinator, their caseloads ranged from 200 to 320 children receiving home and community care resources. Four of the Care Coordinators were registered nurses and the remaining three Care Coordinators were occupational therapists.

\section{Data Collection}

At the beginning of the focus group the researcher attempted to create a trusting and open tone with the participants as suggested by Krueger and Casey (2009). The researcher reviewed the informed consent process and ensured signatures were obtained from all participants prior to starting the focus group. The participants were reminded that all information discussed with the researcher would remain confidential and anonymous. The digital recording was to be transcribed through a reputable transcriptionist and 
transcripts would be maintained by the researcher with limited circulation within the research team. The importance of digitally recording the Care Coordinator focus group discussion to increase rigor and aid in the data analysis process was explained to the participants. All participants were informed that if any participant felt uncomfortable with being recorded they would be allowed to leave at any time without question. Once all signatures were obtained and all participants agreed to begin, the digital recorder was started.

Throughout the Care Coordinator focus group discussion, the researcher encouraged involvement and input from all participants. The researcher was also responsible for moderating the time allocated for the focus group discussion, ensuring that enough time was dedicated toward each question. Lastly, the researcher utilized standard probes when necessary to allow the participants to expand on points and/or to clarify statements they made. Krueger (1998) states that, "probing early in the discussion can be beneficial, sending a signal of the amount of detail sought by the moderator. It's a wise strategy to probe early in the focus group on a topic central to the study. This emphasizes to the participants the importance of precision in responses" (pg. 46).

To fully understand and explore the research question, information regarding the various aspects of caring for a child within the community setting was sought. This included: a) the types of community services families are currently receiving to help care for their child; b) how clients are assessed for home and community care services, the use of standardized assessment tools, and the follow-up processes (i.e. frequency); and c) community services that would help those families better care for their child but are currently not received due to health human resource issues or service availability. 


\section{Data Analysis}

This study focused on the analysis of the 14 LHINs documents and the transcript of the 88-minute focus group discussion with the Care Coordinators. In order to interpret themes and patterns, the researcher undertook content analysis of the data. Neundorf (2002) describes content analysis as a methodology of analyzing various forms of data such as written, verbal, and visual. Content analysis allows the researcher to enhance their understanding of data through the testing of theoretical issues by distilling the data into content-related categories (Cavanagh, 2007). There are several advantages to utilizing content analysis for qualitative data, such as directly examining data in order to understand the central aspects of social interactions, providing insight into human thought and the use of language, and providing insights through the analysis of historical texts and documents.

When performing content analysis of qualitative data, it is imperative to decipher whether the focus of the analysis should be on manifest or latent content. For this research, the analysis of LHIN documents and the Care Coordinator focus group discussion focused on the latent content. This involved analysis of the underlying meaning of the text. A critical component of qualitative content analysis of text is the creation of categories (Cavanagh, 2007). These categories are based on shared commonalities of content. The selection of codes for data analysis was originally developed based on the questions in the interview guide (Appendix C). The purpose was to gain knowledge and an understanding of the Care Coordinator's decision-making process when assessing, allocating, and managing home and community services. 
The units of analysis for this research were documents from 14 LHINs and the transcript of the Care Coordinator focus group. The inclusion of the LHIN documents was necessary to understand the LHIN's priorities as they pertain to the medically complex child population. Within this policy context this research study aimed to understand how Care Coordinators assess, allocate, and manage home and community care services for the medically complex child population. As indicated earlier, the Care Coordinator focus group was conducted prior to a Care Coordinator team meeting at their regional office. With the permission from the focus group participants, two observers attended the Care Coordinator focus group in order to take notes. The Care Coordinator focus group was digitally tape recorded and transcribed verbatim using a professional transcriptionist.

The transcripts were read through multiple times in order to reveal prominent comments, statements and responses, and to obtain a sense of the whole focus group. While reading the transcript, the researcher made notes in the margins of the transcript regarding statements of significance as they relate to the purpose of the study (Krueger \& Casey, 2009). The transcribed data were then divided into codes that had a relationship to the purpose of the study. Based on the review of the transcript and notes of significance, 23 codes were generated. Upon further discussion and review of the data with the thesis committee members regarding the relevance of the codes as they relate to the study, the 23 codes reduced to 18 . The reduction to 18 codes was due to the consolidation of codes pertaining to the increasingly sicker and growth of medically complex child population. For example, five original codes from the first 23 (number of services each client requires increasing, caregiver burden/child comfort levels, palliative 
clients, transitional issues, and falling through the cracks) were collapsed under one code; the 'sicker population/living longer' code. Upon further analysis, the codes were carefully examined to determine how they related to the research question, and ultimately established whether the codes could be consolidated. After careful analysis, the final number of codes totalled 11 . This final reduction was a result of merging of four codes (challenges to delivering services, lack of available services/health human resources, waitlists, and CCAC caseload assignment/workloads) to one code called "system level challenges". A table outlining the steps in analysis and development of codes can be found in Appendix D. Grouping the data into codes allowed for the data to be analyzed individually as well as for comparison between codes, in relation to the purpose of the study. In the following chapters the focus group data was analyzed within each category and discussed as it correlates to providing home and community services to medically complex children and their families. 


\section{Chapter 4 - Findings}

This chapter describes findings from each of the 14 IHSPs released by the LHINs, as well as the experiences from the perspectives of the Care Coordinators when assessing, allocating, and managing home and community care services to medically complex children. The findings are derived from the focus group in which seven CCAC Care Coordinators participated. This chapter reviews the characteristics of the roles and responsibilities of the CCAC Care Coordinators as they relate to the medically complex child home and community care population. A complete list of the codes developed from the analysis of the Care Coordinator focus group can be found in Appendix D.

\section{LHIN Documents}

The findings from the 14 IHSPs released by each of the LHINs revealed only 2 of the 14 LHINs (Hamilton Niagara Haldimand Brant LHIN and South West LHIN) identified priority initiatives focusing on the medically complex child home and community care population. The Hamilton Niagara Haldimand Brant LHIN focused on four key areas to address the needs of the child home and community care population. These areas included: improve the assessment and treatment of mental health services for children; improve the communication of the child rehabilitation network as well as establish rehabilitation assessment and care standards; development of a child knowledge exchange program for health care professionals to access in order to communicate current information; and implement an electronic health record through McMaster Children's Hospital (Hamilton Niagara Haldimand Brant LHIN, 2006). 
The South West LHIN represents nearly 950,000 residents, accounting for approximately $7.5 \%$ of the population in Ontario and is expected to increase by nearly 70,000 residents by 2016 . The South West LHIN projects that the child population will decrease by roughly 15,000 over the next decade. South West LHIN documents highlight as an objective to, "improve the understanding of the availability of and access to health services for children (pre-natal to 18 years old) to identify opportunities to enhance support provided to families through better information and coordination across care providers and partners" (SW LHIN, 2006, p 37). However, no specific plans related to this objective were discussed in this IHSP.

It is apparent that with the implementation of the 14 LHINs in 2007 across Ontario, there was a considerable lack of attention directed to the medically complex child home and community care population. This is indicative of many health system changes that are driven by government as this population is commonly overlooked. Therefore the challenges in obtaining professional services that these medically complex children and their families face while in the home and community setting was not explicitly acknowledged by decision makers as these massive changes in health care restructuring were taking place with the implementation of the LHINs.

\section{Focus Group}

\section{Sicker Population/Living Longer}

A growing trend in the medically complex child home care population is that children are now surviving longer with their complex medical condition, many well into their late-teens and early twenties. The Care Coordinators discussed this in the focus group as a significant factor and they attributed the increasing survival rate of this 
population to the advances in medical technologies and the transfer of this technology out of the acute care environment, allowing many of these children to be cared for in the home and community environments. Although medical technology has facilitated the ability of medically complex children to be cared for outside of the acute care setting, children are being discharged much sicker and are requiring numerous interventions. Two Care Coordinators' comments best represent this, as they stated:

I think the client population coming from the hospital being discharged are sicker, they're requiring more and more interventions, they're living longer and there are more children. I think a lot of children are also premature with a lot of issues that are coming home that would not have necessarily survived before that we wouldn't have seen in the last ten years even.

Another Care Coordinator noted:

...because of the advanced medical knowledge, now we can see that more and more teenagers in our program - because all these children are really with medical needs or complex medical needs, they're growing up so is my case load, I can see a lot of 17 turning 18 or 19 turning 20 or 21 so that group are the group that I find where it's very hard to get them to smoothly transition to an adult case load and then getting somewhere with that.

Several Care Coordinators highlighted that with the medically complex child population living longer, unforeseen difficulties in managing their care have recently arisen. Children are now entering their late teens and early twenties, an age group that previously comprised a fraction of the child home care population. As more children survive into their late teens and early twenties, the Care Coordinators now must manage 
the transition of these children into the adult program of health care organizations. As one Care Coordinator points out:

It's very hard to find primary care for these groups of children. A lot of them don't have doctors that will be able to follow them and that's troubling to know.

Then once you do successfully try to transfer somebody from child and family to the adult program, there is such a huge difference in the services now.

The Care Coordinators highlight that as more children enter their late teens and early twenties, services and service providers are experiencing greater difficulties meeting the needs of this specific age group. One Care Coordinator simply states, "It's not even the 21 [group], it's sort of the 18 to 21 group where they really fall between the cracks, there's nothing there."

\section{Caregiver Burden/Child Comfort Levels}

As the advancement of medical technology continues to increase, medically complex children can be medically stabilized but remain dependent on continual medical interventions that can be performed by a trained caregiver. The Care Coordinators noted that the comfort level of informal caregivers performing medical interventions on a child varies highly in the community setting. Trained informal caregivers perform complex medical interventions such as suctioning, dressing changes, accessing central lines and using feeding tubes. Although trained, many informal caregivers remain intimidated by having to perform medical interventions, no matter how simple or complex. When allocating and managing professional services to children and families, the Care Coordinators indicated that they take the informal caregiver involvement into serious 
consideration, as community resources are limited. This is represented by the following quote:

...there are also issues of parent comfort levels when you're talking about doing complex procedures. Some parents are quite comfortable irrigating central lines and this and that and others are not - they can't do it so you have to assess everybody on an individual level.

The Care Coordinators also commented on how they are expected to allocate professional services for designated periods of time, with the expectation that parents/caregivers will learn how to provide the appropriate advanced level of care their child requires. However, this can be problematic as parents find it difficult or are simply too afraid to perform such complex medical tasks and procedures on their child, as described in the following quote:

...some people just can't do this medical stuff - they can't do it and you know we often have this thing of trying to teach the parents but you need to assess whether we're able to teach the parents or not because they're not able to do this. Their kid is sick, they're stressed, and they're not all able to take on this role of being the nurse and the medical person where some mothers take it all on - it's like no problem. They're taking on all these lines, they're doing it without any question and they want to be the one doing it whereas others can't even look at the needle or look at the syringe, it grosses them out. 
Another interesting trend that was emphasized by the Care Coordinators is the increasing number of children who prefer to learn how to provide their own care, as the overall average ages of the children increases. This was described by a Care Coordinator stating that:

...sometimes we teach older children. We taught one 16 year old to irrigate her own line, she was comfortable with learning how to do it but her parents didn't want her to learn how, they were very anxious but eventually once the parents were comfortable enough for her to be taught, we taught her and it was fine.

\section{Communication with Service Providers/Parents}

The Care Coordinators all view their role as being a vital member of the overall team responsible for the care of the medical complex child as well as the family unit. Since they are consistently communicating with the child and family, the Care Coordinators indicated that they are often the main contact for advice or assistance when families are at their greatest need. One Care Coordinator emphasized this by stating: But we find that sometimes we're kind of standing in those gaps. I don't know that's the trend that I've noticed of late. Coupled along with that I guess part of that is that other community partners, where funding was available for certain programs and for certain benefits, we're finding those are slowly disappearing. All of a sudden everyone is cutting back and it's kind of like we're it - people come to us. 


\section{Decision-Making}

The Care Coordinators directly assess and manage the needs of the child home and community care population. These Care Coordinators function as a self sufficient entity within the organization, and as such, much of the decision-making rests upon each individual Care Coordinator. The Care Coordinators engage in the decision-making process for every new client they assess and on a continual basis thereafter. It was clearly apparent during the focus group that the needs for services far outweigh the supply. As a result the Care Coordinators describe their role as an attempt to meet the expectations of as many families as possible, which may result in some families not receiving all the resources required to meet the medically complex child's needs.

The Care Coordinators illustrated that although their main role is to assess the medically complex child's needs and allocate the necessary professional services, it was imperative that they also assess the entire family unit and consciously be aware of their cultural backgrounds and beliefs. The following quote represents a common view from the Care Coordinators:

The ones that are medically complex are homes visited more frequently because you're doing more changes to the service plan. Also you're assessing whether the caregivers are coping or not. You're not just assessing the child; it's a child and family program because we're assessing whether the caregivers are coping or not and are they managing and do they need to be linked to supports themselves.

Additionally, the Care Coordinators further discussed how critically important it is to also assess the family's ability to cope with the added responsibilities of caring for a medically complex child. With the assistance of the assessment tools and their 
professional practice experience, the Care Coordinators frequently talk with the parents/caregivers about their ongoing ability to cope. This key part of their role is illustrated in the following quote:

I always ask the parents - how are you doing? How are you managing? Are you sleeping? Do you feel the current level of services is meeting your needs? I try to get a picture of how they're managing - even by looking at them. If their hair is all flying apart, they've got the dark circles under the eyes; I sometimes just look at them. A lot of non-verbal stuff, you look at them. You can pick up a lot nonverbally as well, and the other thing you look at is if you have a single parent who is there by herself. Okay, she may need more support. If you have two parents, you also are determining - I find out what is Dad doing? What's Mom doing? Sometimes one may be a lot more involved than the other or one might not be involved at all because they're travelling for work.

The employment situation of those in the household and whether the family has any informal caregivers is an important factor during the assessment process. By gathering this information the Care Coordinator is able to effectively gain valuable insight into the family's financial situation and potential employee benefits the family can capitalize on, but most importantly the availability of extended family members to support and provide care, as demonstrated by this Care Coordinator who stated: You also look at whether the parents are working full time. Whether they're doing shift work. Are there are any informal supports like aunts, uncles, grandparents who are coming in to actually provide - I have one grandfather who comes every morning to get this little girl ready for school then he comes back 
every afternoon to meet her off the bus. She's in diapers and extremely delayed.

He's been doing this for ten years. He's like 80 now. So there are a lot of informal supports that you assess as well.

As Toronto is considered a large urban multicultural setting, there are several different cultural and ethnic backgrounds that the Care Coordinators must be knowledgeable of and be able to plan professional services accordingly. This is best described by one of the Care Coordinator as follows:

Some people have cultural issues too because some cultures are more reluctant to tell you if they're not doing okay. Do you know what I mean? They don't always tell you everything but you have to try to just establish a rapport so that if you need help, if you have any questions, please call me, try to keep that connect there. There are cultural issues too - in some cultures it's expected that the mother do most of the work or it's expected that the family take care of their own and not go to outside so there's a lot of factors related to culture as well that we need to be sensitive to.

Although not directly related to the decision-making process in terms of the assessing, allocating, and managing of home and community care resources, the Care Coordinators expressed a concern for the increasing caseloads/workloads that they were managing. There was a general consensus among the Care Coordinators regarding the concern over the continual growth of their caseloads they are required to manage, and the increasing time required by each client, as the complexity of each client has increased. This may have implications for their ability to effectively manage and adjust the care plans for the children as their caseloads grow. 


\section{Usefulness of Assessment Tools}

During the focus group, an understanding was sought regarding the specific documents and assessment tools used to guide Care Coordinators' decisions when allocating home and community care services. When asked whether children and their families are assessed using a standardized formal assessment tool such as the interRAI, which is used for the adult population, one Care Coordinator simply stated that, "there isn't; there's no formal assessment".

Although there is not a standardized assessment tool, the Care Coordinators discussed two assessment tools developed by the CCAC that are used to determine the needs of the child and family. These assessment tools are utilized to aid the Care Coordinators in determining how many hours of professional services such as nursing services and personal support worker services to allocate to each client. As will be discussed below, these tools have been deemed by some Care Coordinators as not being "sensitive enough" to capture the needs of the family. Most importantly, the Care Coordinators highlight that other than these two assessment tools and their own professional experience, there is currently no standardized national or provincial assessment tool that effectively assesses the needs of this population. Additionally, the absence of a standardized assessment tool has brought a new challenge to the Care Coordinators, the ability to seamlessly transition the children into the 'adult program'.

When discussing which assessment tools are utilized to aid in the decisionmaking process regarding the allocation of services, the Care Coordinators were in full agreement with the fact that the current assessment tools had inherent issues. These issues discussed by the Care Coordinators were that the assessment tools were not 
sensitive enough to the needs of the paediatric population and capturing the family's ability to cope with the additional care responsibilities. One Care Coordinator highlights the issues regarding the current tools, stating that:

We have two assessment tools that we use. Basically there is one to assess personal support and one for shift nursing. I think my colleagues here will agree with me that sometimes these tools aren't sensitive enough to pick up what we want them to pick up so even though we do the assessment, you still have to take a step back and look at that family situation. Try your very best to come up with the hours you think that they should fairly receive and that's a tough thing to do. Many Care Coordinators emphasized the importance of doing a home visit with the family and the child present in order to properly assess the needs that could not be captured by the current assessment tools. Ultimately, this requires the Care Coordinators to base their decision-making on their professional experience, going beyond the results of the assessment tools. The Care Coordinators attributed the need for this to the uniqueness of the population, which the assessment tool is unable to capture, as well as the information gathered from the family/caregivers regarding the child's care needs. One Care Coordinator pointed this out in the following statement:

Most of the information comes from the parents. We basically have a set number of questions that we ask them for the two tools - the PSW and the shift nursing so we go through the questions with the parents and go from there. Rarely do we ask the children because if they're getting PSW or shift nursing services, mostly those children have developmental delays so they wouldn't be able to answer those questions anyway but we do go in and observe the child, we see them in their 
home setting which we then get an idea of what's going on with the child while we're there. We don't actually do any clinical assessments with the children but we sort of take most of what the parents say at face value.

In addition to using the assessment tools and conducting a home visit, the Care Coordinators indicated that they frequently rely on each other for advice and consultation when challenged with a specific child or family situation, as described in the following quote:

Well, plus consultation with our peers. You know I think that when we have those tough cases, you do consult with each other because other members of the team may have had a similar case or they may have gone a similar route so you kind of tap into those resources. Talk to your manager. Sometimes even talking to an adult coordinator for certain issues you know but yeah, we really don't have anything beyond those two tools. We have our eligibility guidelines to be admitted for service then we have our sort of formal service guidelines.

\section{System Level Challenges}

It is clear that the Care Coordinators are faced with assessing and managing a unique and challenging home care population unlike any other population managed by the organization. Not only is the population unique, the Care Coordinators indicate that they are facing challenges they did not encounter as little as 5 to 10 years ago. As previously discussed, more children are surviving medically complex conditions, many surviving due to the advancement of medical technologies that have allowed children to be effectively supported and medically managed and therefore enabling them to be discharged from the institutional setting. Due to these factors, children are living longer 
with their medically complex conditions, thereby greatly increasing the overall population living in the community. This has placed a significant strain on community resources, creating waitlists for professional services that are considered vital to these children and their families.

The Care Coordinators discussed the huge challenges they faced each day in trying to locate and manage the delivery of services to the medically complex child. From the focus group discussion it became very clear that the Care Coordinators face many difficulties that may delay or prevent the child from receiving services in the home and community setting. The Care Coordinators addressed three key system level challenges that they face when allocating and managing home and community resources. These key system level challenges will be described under the following three categories: 1) Lack of available services/health human resources, 2) Waitlists, and 3) Differences in policies/protocols among differing Community Care Access Centres across Ontario.

\section{Lack of available services/health human resources.}

There was a general consensus by all Care Coordinators that there is a significant health human resource shortage in the area of home and community care in Ontario. There is an even greater shortage of health care professionals with knowledge in paediatric care within the community sector. Additionally, as will be highlighted below, many of the professionals working in the home and community setting have been working in this health care sector for multiple years. As indicated by the Care Coordinators, many of these professionals are not up to date with the knowledge and skills in the area of medical advances especially around the various technologies and 
medical equipment with which children are being discharged home, as compared with those working the acute care settings.

One Care Coordinator discussed that due to the health human resource shortages in the community she experiences great difficulties in obtaining the needed amount of shift nursing for her clients, as this is one of the most heavily utilized services by children with complex care needs. She described these difficulties as follows:

What happens is you can get a request for shift nursing and you can contact every agency we contract with and none of them can take the client so you end up putting in visiting nursing instead. That is a huge trend that I've noticed. Especially if people want service in the evening or at night or on weekends, it's becoming extremely difficult to get. I've had one client downtown who has been waiting for more than a year to get a shift nurse to do Saturday evening...they've got other hours throughout the week but this Saturday evening spot - nobody is touching it.

Although there are nurses in the community to provide nursing care, with the increasing complexity of care required, many nursing agencies outside of the metropolitan area either do not have enough staff trained to provide the level of care required or simply do not provide that level of care. This is highlighted in the following statement from one Care Coordinator:

When you phone [another] CCAC and talk to an intake coordinator, they'll just say we don't have any paediatric nurses. Usually the biggest reason is they can't find a paediatric nurse to do the procedure. The second biggest reason is some of them won't administer certain high risk medications to children under a certain 
weight or they won't deal with a port-a-cath or a central venous line on a child under a certain weight. That may again be back to the lack of nursing availability which I think it may be back to that and maybe the lack of contracts with paediatric nurses or lack of expertise.

The Care Coordinators also indicated that another issue in the home and community care sector is the high turnover and lack of retention of health care professionals. The high turnover of health care professionals in the community places a great strain on the children and families receiving those services. For the Care Coordinators, the high turnover complicates their ability to effectively manage the care of the child and family in the community. One Care Coordinator expressed their experience when challenged by the high turnover of health care professionals in the home and community sector, stating that:

There's also quite a turnover of therapists so that sort of throws a wrench into things because a child might have been ready to be picked up or they might have started service then the therapist leaves, then the agency would have to find another therapist to take it over.

The situation of attaining and retaining professionals with paediatric knowledge and expertise is a serious and growing concern for the Care Coordinators. The following quote was a common theme represented by the Care Coordinators:

Yeah, definitely the retention in recruiting for community - community professionals. This trend has been all along. I mean a lot of people - nurses graduate or whatever, they go to hospital jobs. There's collegiality there, there's support, not a lot of people venture into community right when they graduate. To 
talk provincially, I don't know if you guys saw the Toronto Star there was an article about - we all know that homecare is really the future of healthcare in the province and beyond but in order to be great, we need to have the workforce and the human resources and the financial resources to support from the province.

The Care Coordinators note another reality in the home and community sector - an aging workforce. They indicate that they are finding fewer professionals entering this sector, and those professionals that are currently practicing in the home and community setting are getting older, placing more personal restrictions on their professional practice, and retiring, as described in the following quotes:

...even when they do get shift nursing, I think this is a real issue within the nursing community is that the nurses are old, they're not able to lift these young children, they're just not doing as much as a younger nurse might do.

A lot of the shift nurses are older and the younger ones don't seem to want to do the shift nursing assignments - I've noticed that most of my shift nurses are older - I mean over 50.

Another Care Coordinator highlights that beyond the aging nursing workforce, they have been experiencing major shortages across the entire province within numerous other health care professions such as physiotherapists, occupational therapists and speech language pathologists. These challenges of health human shortages were summarized by one Care Coordinator as follows:

...there are lot of things that are beyond our control that are happening out there with service providers; there's a shortage of nurses, shortage of paediatric, OT, speech and physios and I think that that has been getting worse across the board. 
It's not just here either, I think it's throughout the entire province and I think some of the smaller communities are even more affected then we are so I think that's huge.

These health human resource shortages across the province pose enormous challenges when trying to coordinate home and community care services for medically complex children when the family resides outside of the Toronto area. As was highlighted in the focus group discussion, the availability of home and community care resources, as well as the policies and protocols of the agencies that provide professional health care services varies considerably across the province. This is an issue that the Care Coordinators must be conscious of, as many medically complex children do not live in the Greater Toronto Area but attend clinics associated with paediatric tertiary care centres in the Toronto area, where much of their primary health care team is located. If the health care team changes the treatment plan for the medical management of the child, the Care Coordinators must ensure that these changes can be supported in the child's community before they return home. As emphasized by the Care Coordinators, when the medically complex child cannot be supported, due to the inability to provide the necessary services or a lack of resources in their region, the child and family's only option is to remain in Toronto in order to receive the appropriate level of care. They may remain in the acute care setting, move to Ronald McDonald House, or stay with family or friends for an extended period of time. This places significant stress and burden on the child and family, who did not plan on remaining in Toronto. 


\section{Waitlists.}

The Care Coordinators expressed great concern regarding the growing waitlists for home and community care services for this particular population. As discussed earlier, more children are being discharged quicker from acute care settings and with increased medical complexity, coupled with a health human resource shortage in the community. Since the Care Coordinators are responsible for managing and allocating the delivery of services and not directly providing professional home care services to the child, service provider waitlists are out of the Care Coordinators' control. The Care Coordinators indicated that provider waitlists are a necessary method in dealing with the increased demands and limiting health human resources for professional services. Several Care Coordinators expressed frustration regarding the waitlists, as exemplified in the following quote:

The waiting lists are growing longer and longer. There's actually two waitlists to be quite honest and we're trying to manage our own queue; hopefully as we get referrals we're trying to move them on to the provider queue but there's always a queue and the number of children that are being referred from school has just, for some reason, it's increased so much, every year it's increased. It seems like every single child is being sent our way and sometimes when it comes down to doing the actually assessment, some of these kids really don't need CCAC services.

From the discussions during the focus group, it is apparent that the Care Coordinators have little to no control on the waitlists children are placed on. The Care Coordinators indicated that they receive referrals for new clients on a daily basis, a volume that far out- 
weights the supply of resources. Therefore, in the quote above, the Care Coordinator discussed the need to create a 'second' internal waitlist for new client referrals.

\section{Differences in policies/protocols.}

The Care Coordinators indicated that there is a lack of communication and understanding between hospital and community regarding the current availability of community health care services across the province before a client is discharged from the acute care setting to the home. They indicated that the expectations and lack of communication of acute care staff did not give Care Coordinators sufficient time to plan and coordinate services for families, especially for those children who live outside of the metropolitan area, before they are discharged home. The lack of communication results in possible delays in receiving home care services or even delayed discharges from hospital, causing significant frustration and dissatisfaction among families.

As one Care Coordinator indicated, she is frequently faced with the challenge of managing and coordinating services for children who must remain within the Greater Toronto area. These children and families have been discharged from the acute care setting, but still require professional services in the community setting. This Care Coordinator emphasized that due to variations in policies and protocols of professional services across Ontario, there are situations in which these children have to remain in Toronto in order to receive vital health care services. The following quote from a Care Coordinator provides an example of the increasing difficulties in managing children and families who are unable to return home due to the policy and protocol constraints across the province: 
There are several CCACs who do not [provide] IV hydration at home for children or they won't administer certain medication intravenously or they won't deal with a central venous line on a child weighing less than so many kilograms. There's all these different rules but the bottom-line is a lot of the Ronald McDonald House clients, SickKids will feel they're medical stable enough to return to their home address then when we try to transfer to their home address, there is sometimes lack of nursing; there just isn't anybody or sometimes there's policies around that particular CCAC not doing a central venous line on a child under 10 kilograms or not administering certain medications on child less than a certain weight or just not administering medication because it's high risk so what happens is they end up staying at Ronald McDonald House.

Lastly, a common issue with children and families that live in rural areas of the province is the lack of available professional services. As the complexity of the health care requirements and the need for multiple professional disciplines increase, providers in the rural areas of the province are finding it difficult to accommodate the demands. The following quote from a Care Coordinator highlights difficulties they face when a child is discharged from the acute care setting without securing the required professional services:

...they want to transfer them back to their home address and when there's a lack of nursing at the home address or they refuse to do a certain procedure, they end up staying at Ronald McDonald House for months. So we got stuck even though the medical care part at SickKids will transfer from SickKids to Toronto General 
Hospital...but our part is still stuck here because nobody wants to take in these children...

With the three major system challenges outlined above: 1) Lack of available services/health human resources, 2) Waitlists, and 3) Differences in policies/protocols among Community Care Access Centre's across Ontario, it is clear that the Care Coordinators are challenged to provide professional services to these children and their families. The Care Coordinators must always be cognizant of these system level issues as it may delay the child's discharge from the acute care setting, making them remain in Toronto, or may place the child and family at risk if insufficient home and community services are available.

\section{Economic Downturn}

The Care Coordinators highlighted the recent turbulence the home and community care sector experienced in Ontario as a result of the effects of the economic downturn that began in late 2008 and continued through 2009. From the Care Coordinators perspectives the economic downturn had an impact on the children and families who rely on community resources, as it affected the amount of government funding for special services and programs that many relied on. Several Care Coordinators discussed the effects of the economic downturn stating that:

Just before the big downturn, we had this big announcement how we were going to give all this money to home care. We had increased our maximums for PSWs for a number of different services and then two months later it was no, no, we're 
not going to do that, we're actually going to cut back so it's funny that these things turn out this way.

Not only had the economic downturn impacted those children and families previously receiving services, the greatest difficulty for Care Coordinators was supporting new children and families to the program. A Care Coordinator highlighted how the economic downturn has affected new clients to the system, stating that:

There is one fund that I think is directly related to the economic downturn - I think with special services at home - they have now waitlisted their funds that says basically anybody who is new coming into the system who needs funding will not get it. Then that was just more recent and I think that is related to the economic recession.

Lastly, one Care Coordinator expressed her frustration with the availability of additional funding for families in need during the economic downturn stating that:

They are not processing any intake [funding applications] and yet when you call they say well, tell the parents to fill in the form and send it in, we'll keep it and when the funding is available then we'll process which really is affecting our work and also allocation of service because well, if they don't get in from... at a set age...they're needing the service, where else can [families] get it?

\section{Team-Based Approach}

The role of the Care Coordinator can be viewed as an independent professional responsible for assessing, allocating, and managing home and community care services. All Care Coordinators are equipped with a laptop and a cell phone that provide them with remote access to the CCAC client database and communication with colleagues and 
clients. Although each Care Coordinator operates independently, managing their own caseload of clients, there was a general consensus among all the Care Coordinators of the importance of being part of a larger team. Care Coordinators had various professional backgrounds, which included registered nurses, physiotherapists, occupational therapists, speech language pathologists, and social workers. As one Care Coordinator highlighted, having a team consisting of a variety of professionals was a significant asset as described in the following quote:

What I find really nice about this team and the larger colleagues in the organization is that we all come with different professional backgrounds and there may be a point in time where you need to access someone with a nursing background, their expertise and skill. Other times you look to the OT or the social worker and it's quite nice to have that mix rather then having it just homogenous - you know one type of professional.

When Care Coordinators are faced with a unique client and/or family situation, they frequently rely on their colleagues for consultation. If the situation is significantly complex, the consultation process could develop into a team conference, as one Care Coordinator indicated with the following quote:

... if there's a complex situation, we would have a case conference with perhaps all the providers and all the community resources in the home so see who is going to be doing what and what's happening. If a child gets to a point where they've met their goals or they're not going to be making any further progress, then we have to re-evaluate - are we still going to continue to put that service in and at what level. 
However, as several Care Coordinators discussed, the flexibility and autonomy can create issues such as a sense of isolation and lack of collegial support. This is a significant change for many Care Coordinators, as a major characteristic of their professional backgrounds (i.e. nurse, occupational therapist, social worker, etc.) is working in an inter-professional, multi-disciplinary team environment. As one Care Coordinator stated:

I think from a work process standpoint too, one of the big changes we've had is all the IT changes so that we are now all working out in the community, we're all now separated from each other so there's no more of that [once a month] meeting together in the office and discussing situations and working through issues like we were able to do in the past. We can still do that but it's now via e-mail or telephone. It's just not the same connection with each other.

\section{Quality Assurance}

A major role of the Care Coordinator is to act as a liaison between the child/family and the professional service providers. When information regarding service quality, change in client's status, or change in family status needs to be conveyed, the Care Coordinator becomes involved and is responsible for investigating the issue. One Care Coordinator discussed the process she must undergo when an issue arises, with the following statement:

Usually I would take down the information and I would let the parents know what I will be going to do. I will talk to the nurse and if you see that there is really two sides of the story or a communication difficulty, usually I will call for a 
conference with the service provider, the parents, and us to talk and try to soothe things.

As many of these medically complex children will require professional interventions for the majority of their lives, families are informed that they can contact the Care Coordinator whenever an issue arises. Unfortunately children and their families are not given a forum to which they can formally evaluate the services they are receiving. Their only route to voice their concerns is to contact their Care Coordinator or notify the specific agency. But, when asked whether the parents/caregivers are able to formally evaluate the services they are receiving, one Care Coordinator indicated that:

They do but I don't know how often they do it but there is something that exists called the Client Satisfaction Survey and that they were calling the parents but I don't know how often the do it or when they last did because we haven't heard anything about it recently but I know at one point they were doing it on a regular basis and it may be that they're still doing it, I don't know. I don't think they are still doing it because I can remember that when they were doing it, they would send out the list of kids and we had to contact the parents, ask consent and we haven't been receiving this information for at least the last three to four years. The Care Coordinators indicated that although there was not a formal evaluation of services currently in place, they do inform the children and families of their rights as consumers and their right to refuse a specific care provider. Additionally, the Care Coordinators highlighted that families can undergo an appeals process if they believe they are not receiving the fair and equitable amount of home care services to which they are entitled. While an informal appeals process where families can discuss any issues 
regarding entitlement to services is currently in place, many of the Care Coordinators remarked that many families do not pursue this option.

One Care Coordinator stated that she gains significant insights about the status and quality of service provided to the child through the mandatory service reports that all professional service providers must submit. These reports are completed during the initial visit by the service provider and are submitted on a regular basis thereafter. These reports allow the Care Coordinator an opportunity to liaise between the service provider and the child. This was described as follows:

The other place too where you get information is the service providers that are in the home. You know if it's nurses or OTs or PTs they're providing us reports on a regular basis so - we speak with them as well so they're always a good source of information on what's going on with the child.

\section{Changes Since the Implementation of the LHIN's}

During the focus group, the Care Coordinators were asked to comment on what, if any, changes occurred within their practice after the implementation of the LHINs. The majority of Care Coordinators highlighted the dramatic increase of clients on their caseloads, one Care Coordinator stated that "I think I had about maybe 120 to 150 [preLHINs] and now I've got 320". Not only were the Care Coordinators' caseloads increasing, but they were also experiencing waitlists for services that previously did not have waitlists, causing stress for many families. Lastly, the Care Coordinators discussed that with the implementation of the LHINs their geographical catchment areas for their caseloads had grown significantly. With the larger caseload boundaries, meant Care 
Coordinators had to travel much farther to conduct initial assessments or make any necessary follow-up home visits.

\section{Future Transformation of Home and Community Care Services}

At the end of the focus group, the Care Coordinators where asked to discuss what if any, changes they would make, if they were given the opportunity to transform home and community care services. All Care Coordinators shared their visions to transform home and community care services for children and provided different and unique changes. Interesting to note was that whenever a coordinator shared their vision, several of the other coordinators were in agreement.

The Care Coordinators shared their visions for change, discussing the need for all agencies/organizations/governments to understand, communicate, and collaborate with one another for the benefit of the child and family. Through a greater understanding of organizations and services, communication between such organizations would increase and ultimately aid the child and family through any major events or transitions. This in turn would improve the quality of life of the child and family, as indicated by this Care Coordinator, who stated:

You know what I'd like to see? We know what role we have to play within the CCAC there are a lot of partners that we work with. It would be nice if everybody knew what they needed to do and just did it...That's what I would like to see just more, less disjointedness. More of all of us working together and doing our piece for the benefit of that client. 
One Care Coordinator reflected on the need for an increase in funding for home care services and programs specifically for medically complex children. The Care Coordinator highlighted that if adequate funding was in place for this population, waitlists would be non existent or significantly decreased and she would be able to effectively and efficiently support the child and their families, stating:

I think more funding might enable us to provide services more proactively because I think a lot of us feel that we're just reacting to the things that come up and sort of keeping things sort of settled down but I would imagine that most of us don't feel that we're able to sort of go out and set up situations that are going to end up working out better for the families and for children because the case loads are too high or the services aren't available.

One Care Coordinator's vision involved an expansion of community services programs, particularly within daycare centres. Within Ontario, professional services do not enter the daycare environment. Although these children are too young to be within the school system, many of them still require vital community services, as the following quote indicates:

Right now that's [daycare centres] not under our jurisdiction but there's a real gap there, very limited service and if there was more funding we could address - I find a lot of those kids are falling through the cracks. They're not in school yet but they're not under CCAC service and children in daycare have minimal access to occupational therapy, no access to physiotherapy or the other services. If we had more funding, I would love to be able to provide care to them. 
The Care Coordinators addressed the global issue of the lack of health human resources within home care in Ontario. This issue has affected numerous service providers and is a clear indication of the need for more government funding to be allocated to the home care sector, as well as the growing demand for health care professionals in the community. This was best described in the following quote stating:

I think the human resource issue is huge though. The human resource issue related to the lack of nursing in the community, lack of paediatric OT and paediatric physio and even it's getting to the point where trying to recruit for our jobs is becoming more difficult...If you don't fix that, you're still going to have a huge problem on your hands.

Lastly, one Care Coordinator addressed the need for improvements in hospital discharge planning. This would include an increased level of knowledge from the medical team in the hospital regarding home and community services, the differences in available services depending where one lives in Ontario, and a higher level of communication between hospital staff and Care Coordinators. Ideally, this Care Coordinator envisions being part of the hospital team as a representative from the community rather than receiving a list of professional home and community services required by the child for discharge home. One Care Coordinator explained this with the following statement:

I'd like to see when these complex kids come out of the hospital, some real discharge planning where we'd actually go in there and say well these are the things that the child needs... 


\section{Summary of Findings}

This study was based on the belief that the medically complex child home care population is a complex and unique population. As one Care Coordinators stated: "the main point is they're so complex and fragile". Findings from the study conclude that the Care Coordinators who are responsible for assessing, allocating, and managing services are faced with many challenges that have affected their ability to effectively provide the level of care and service allocation that meets all the needs of their clients. As the Care Coordinators indicated, there are multiple factors that have caused not only increases in the population of medically complex children but also increases on their caseloads. Since many of the regions throughout Ontario do not have adequate resources to care for these children in the home setting, Care Coordinators expressed difficulties in securing home and community care resources when leaving the acute care setting.

It is apparent that the work of a Care Coordinator is complex and requires significant case management skills in order to meet the needs of the child and family. Additionally, the Care Coordinator must always be aware of the organizational budgets, priorities and service maximums. With this in mind, the Care Coordinators were in agreement that the current assessment tools help guide their decision-making but it is imperative that their professional experience, assessment skills, and their knowledge regarding the needs of this population be implemented when allocating services. 


\section{Chapter 5 - Discussion and Study Implications}

\section{Introduction}

The main purpose of this study was to gain an understanding of the Care Coordinator role and the decision-making process when assessing, allocating, and managing home and community services for medically complex children and their families. This chapter discusses the current literature and its relationship to the key findings. It addresses three major areas from the findings: 1) Family burden, 2) Health human resource challenges, and 3) Street-level bureaucrats. Additionally, this chapter discusses the implications of the findings for health policy and research.

As indicated earlier, this study is timed particularly well, as the Ontario health care system underwent a major restructuring with the implementation of the LHINs in 2007. As part of the LHINs' mandate, there was an expectation that there would be a shift in resources from institutions to the community to meet the increasing demand for home and community care services. This increased focus and reliance on home and community care services across Ontario resulted in CCAC Care Coordinators facing a greater demand to assess, allocate, and manage these services for children with medically

complex care. All of the Care Coordinators who participated in the focus group were in their current positions both before and after the implementation of the LHINs. This allowed the Care Coordinators to provide significant insight and knowledge into the differences they had experienced in the areas of health care funding, allocation, and management of the home and community care services since the inception of the LHINs in 2007. 


\section{Family Burden}

In terms of the medically complex paediatric home and community care population, all of the Care Coordinators were able to express the significant changes they have seen in this particular population. The Care Coordinators all discussed how they have witnessed a very significant increase in both the number of children requiring professional home and community care services, and the level of medical complexity involved in their care. This finding is consistent with the literature, which indicates that due to technological, pharmaceutical, and diagnostic advances, the mortality rates of children with medically complex conditions have drastically dropped, allowing these children to live longer and fuller lives with their medically complex condition (Cohen, Friedman, Nicholas, Adams, \& Rosenbaum, 2008; Kirk, 2001; Spalding, Hayes, Williams, \& McKeever, 2002; Wong, 1991).

As was highlighted in the literature, families may face increased levels of stress, caregiver burden, social isolation, financial losses, and an overall decrease in quality of life (Bremberg, 2002; Carnevale, Alexander, Davis, Rennick, \& Troini, 2006; Kirk, 1998; Kuster et al., 2004; Perrin, et al., 2007). Similarly, the Care Coordinators in this study identified how families continue to deal with stress and the burden of the expectation that they will be independent in performing the care responsibilities and monitoring the overall health status of their medically complex child when discharged home. Wang and Barnard (2004) report that fear and stress among parents and caregivers exists, revealing the parental fears associated with performing procedures, utilizing medical equipment, comprehending complex medical information, harming their child, and potentially finding their child dead. Although there is this expectation for families to be competent 
at performing any additional care responsibilities, the literature emphasizes the importance of initially providing sufficient home and community care resources to meet the care needs of the medically complex child and family (Cohen, Friedman, Nicholas, Adams, \& Rosenbaum, 2008; Spalding, Hayes, Williams, \& McKeever, 2002; Wang \& Barnard, 2004). For each client, gaining an understanding of the child and family's knowledge, comfort, and abilities to perform the medical care responsibilities is imperative during the initial assessment and any further assessments that are completed by the Care Coordinators.

As the complexity of this population increases, the Care Coordinators indicated the importance of not only assessing the care needs of the medically complex child but also the needs of the family overall. All of the Care Coordinators had extensive years of experience in assessing, allocating, and managing home and community resources, and many of them had been managing the same medically complex children and their families for several years. The Care Coordinators stated that the child population currently does not have a standardized assessment tool, similar to the interRAI used in the adult population. The literature also indicates that for the medically complex child home and community care population, no standardized assessment tool currently exists (Cohen, Friedman, Nicholas, Adams, \& Rosenbaum, 2008; Spalding, 2005). Even with their years of experience, the Care Coordinators indicated that every medically complex child and family have unique needs, and therefore it would be difficult to implement standardized assessment tools to determine the allocation of professional home and community care services. In the Spalding (2005) study, a similar attitude toward the implementation of standardized assessment tools was also reported. Although the 
uniqueness of the adult population is also true, as there are multiple factors that must be taken into account regarding their care needs in the home and community setting, the assessment process is guided by a standardized assessment tool. The Care Coordinators attested that a standardized assessment tool for the paediatric population would eliminate their current discretionary power to allocate appropriate services, a factor that would have more profound effects than that with the adult population. Depending on their medical condition, these children can be continually transitioning into new developmental stages at the proper age, be delayed, or not advance to a new developmental stage at all. Due to this factor, the Care Coordinators indicated that it would be difficult to capture and allocate appropriate services with use of a standardized assessment tool. Spalding, Hayes, Williams, and McKeever (2002) discuss the importance of providing services linked the child's progression through developmental stages and not solely on their diagnosis.

The use of a formalized assessment tool could assist the Care Coordinators and the organization to demonstrate to policy-makers the need for government to dedicate a more appropriate level of resources to this growing population. An important benefit of having a standardized assessment tool is its ability to highlight any disparities between supply and demand, which in some instances could provide essential data for decisionmakers when attempting to address the health human resource shortages in the home and community care sector. 


\section{Health Human Resource Challenges}

All of the Care Coordinators spoke at a great length about the health human resource shortages in the home and community care sector within Ontario, with a particular emphasis on the shortages of professionals with a specialization in paediatrics. With the increasing pressures to effectively fund and manage the health care system in Ontario, acute care institutions are forced to cut acute care beds and shorten hospital lengths of stay (Spalding, 2005). This results in acute care institutions resorting to discharging patients sooner, and often before they can ensure all the necessary home and community care services are put in place. Previous studies have also shown that as these broader system challenges and issues devolve to the home and community sector, many individuals remain without professional health care services, which can severely affect vulnerable populations such as medically complex children. (Baranek, Deber \& Williams, 2004; Spalding, 2005; Williams, Deber, Baranek, \& Gildiner, 2001). With the increased pressure to discharge patients who still require professional health care services from acute care settings to the community, the Care Coordinators expressed frustrations in locating appropriate home and community resources to meet the medically complex children's and families' needs. As a direct result of this, Care Coordinators explained that some medically complex children and their families are being placed on waitlists for professional services and some families are expected to manage on their own until the required services are started. Given that there is a high demand for services, and in an attempt to minimize the length a family remains on the waitlist, as well as the overall number of families on the waitlist, services would be put in place in hopes that families would take over the necessary care responsibilities. In the 
Spalding (2005) study, similar results were found, showing that many of the Care Coordinators in the study would allocate hours to the medically complex child in order to teach the child, family members, or teachers how to provide the necessary care the child requires. When these individuals are taught and comfortable to perform the necessary care responsibilities, Care Coordinators are then able to remove them from their caseloads and address those children still on the waitlist for services.

The literature indicates that parents recalled little discussion with professionals regarding the care responsibilities for their medically complex child prior to discharge from institutional care (Kirk, 1999; Ray, 2005). As a result, many families experience great difficulties when their medically complex child is first discharged from the acute care setting, also supporting the evidence of high levels of family/caregiver stress. In addition, parents feel a sense of obligation to bring their child home regardless of their condition in hopes of increasing the child's quality of life and reducing the disruption to the family as a whole (Kirk, 2001). Kirk (2001) also identified that there is no mechanism to assess the parental perspectives and abilities, as they will be responsible for caring for their medically complex child prior to discharge from institutional care. Ultimately, the literature has demonstrated that too many of these children and families are being discharged to the home and community setting, some for the first time since their birth, without an effective discharge plan (Kirk, 2001; Spalding, 2005).

As Kirk (1999) demonstrates, there needs to be a greater emphasis on providing professional supports for families in their homes, since the site of care has shifted from the acute care setting to the home and community care setting. In addition, Ray (2005) emphasizes the importance of improving the integration of home and community care 
resources as they are currently fragmented across multiple levels of ministries and departments, all of which have differing service criteria and qualifications, resulting in fragmentation across services within the Canadian context. The Ontario government has several ministries and departments involved in the care of medically complex children and include, but not limited to: the Ministry of Health and Long-Term Care, Ministry of Community and Social Services, Ministry of Education, Ministry of Family and Community Services, and Ministry of Child and Youth Services. Parents of medically complex children, as well as the Care Coordinators, must be cognisant of the eligibility criteria for service and funding provided under each ministry or department, as well as all the other organizations, service agencies, and schools from which the child receives support. The Care Coordinators in this study also identified the need to address the fragmentation across numerous ministries that they and families must contend with.

As previously discussed, home and community care services fall outside of the CHA. This poses potential difficulties for medically complex children and their families who are not in the acute care setting but who are still in need of a high level of care. Vitally important for the medically complex child is that all individuals involved in providing professional health care services collaborate and communicate with one another, as each professional has the opportunity to change treatments or make recommendations for care. During the focus group discussion, the Care Coordinators emphasized that for a successful transition of a medically complex child, communication and coordination between the medical team, Care Coordinators, and family is necessary prior to being discharged from the acute care setting. When a breakdown in communication and coordination arises, family stress levels increase and burnout may 
occur, leaving families with no one to turn to other than the Care Coordinator for assistance or solutions. A previous study by Rosenbaum (2008) emphasizes the importance of communication and coordination for families with medically complex children, since these children typically have numerous professional health care services provided in both the acute care setting and in the home and community care setting. Without the mechanisms for communication and collaboration, Rosenbaum (2008) warns of creating a fragmented system which can ultimately jeopardize the health of the child and family. The Care Coordinators also emphasized this point, indicating that they are often the intermediary between the family and the professional service providers. Additionally, the Care Coordinators highlighted that they often find themselves filling in the communication gaps between the acute care setting and the home and community care setting.

With the implementation of the LHINs there has been an increased governmental demand placed on health care organizations to ensure financial accountability. For the medically complex child home and community care population, demonstrating financial and professional accountability to the government is critical in order to maintain a level of professional home and community care services that continually meets the needs of this population. The Care Coordinators indicated that just as there is no assessment tool to evaluate medically complex children's care needs, there is no formal mechanism to assess the quality and effectiveness of the care that is provided to the medically complex child and family. The literature also indicates that there are currently no adequate mechanisms to monitor or assess the quality of nursing care provided, whether within the acute care setting or home and community care setting (Sidani, Doran, \& Mitchell, 2004). 
Although there are no developed mechanisms to demonstrate the effectiveness of nursing services, Doran, Harrison, Laschinger, Hirdes, Rukholm, Sidani, et al. (2006) discuss that nursing interventions on individuals are correlated with positive outcomes both in functional status and self-care outcomes. Unfortunately, no studies have attempted to measure these outcomes for the population of medically complex children.

\section{Street-Level Bureaucrats}

Of utmost importance is the understanding that professional home and community care services fall outside of the Canada Health Act, and therefore citizens are not universally entitled to receive home and community health care services. However, within Ontario, individuals are entitled to be assessed for home and community health care services, upon assessment by a CCAC Care Coordinator. If the Care Coordinator deems the individual in need of these services to remain healthy and independent in the community, certain services will be provided at no cost to the individual. The CCACs are regulated by the Ontario government however, the government maintains a limited role in controlling and overseeing financial rights and responsibilities. Ultimately, financial discretion and the allocation of services and resources are left at the Care Coordinator level. This discretionary distance allows the provincial government to maintain their public policy responsibilities by controlling costs, but minimizes its public accountability through reliance on Care Coordinators to assess, allocate, and manage home and community professional services.

The Care Coordinators' experiences in the decision-making process regarding the allocation of professional services for medically complex children, closely corresponds with Lipsky’s (1980) concept of street-level bureaucrats. Lipsky (1980) describes public 
workers having significant discretion in the manner in which they implement their work, and this parallels the situation with the Care Coordinators in the CCACs. The Care Coordinators have a high level of discretion as to the type and amount of professional home and community care services a medically complex child and their family will be allocated. Although one could argue that it is unnecessary for front-line workers such as Care Coordinators to have such a high degree of discretionary power, in reality it is imperative that the Care Coordinators have some discretion, as there is significant variation among children in relation to medical complexity, medical diagnosis, family and caregiver supports, and the socioeconomic status of the family. Assessment tools may not be sensitive to these important variations, thus it is important that Care Coordinators have this level of discretionary power in allocating professional health care services.

The Care Coordinators take on sole responsibility of assessing the children and also have discretion of which services to allocate and deliver. The only protocol the Care Coordinator must abide by is the service maximums as set by the government and the CCAC. During the decision-making process, when the Care Coordinators are allocating professional services to children and families, the Care Coordinators indicated that they take the informal caregiver involvement into serious consideration, as community resources are limited. Additionally, Care Coordinators often investigate other sources of support that are available to the families. Such sources include employment benefits and insurance policies, charitable organizations, and availability of siblings or extended family members. Faced with system level pressures on a daily basis and challenged by the lack of a standardized assessment tool or eligibility criteria to assess medically 
complex children for home and community care services, Care Coordinators act as streetlevel bureaucrats, implementing their own policies to meet the needs of the population.

As there is no standardized assessment tool that Care Coordinators must abide by, they are able to provide the level of service, within the service maximums set by the organization, that they believe are necessary. Lipsky (1980) insists that street-level bureaucrats, such as the Care Coordinators, need to have some discretion and flexibility in order to effectively meet the demands of the medically complex child population, and that fully bureaucratizing the system is not ideal. Additionally, Lipsky (1980) highlights that the actions of street-level bureaucrats are indirectly creating public policies which are being enforced at the front line level, directly affecting the population they are serving. The decisions that Care Coordinators in this study make are, in fact, creating policy rather than being influenced by policy. As was highlighted in the Care Coordinator focus group discussion, children and families have very little means of appealing the allocation of services and have little basis for framing their appeals, as no formal comprehensive assessment is documented. Without the implementation of a standardized assessment tool, Care Coordinators continue to have a high level of discretion regarding the allocation of services, with many families remaining unaware of their entitlement and rights. Furthermore, families are left without the ability to formally appeal the allocation decisions about home and community care services their child receives with the organization. By supporting a system that implements a balanced approach which utilizes a standardized assessment tool, as well as allowing for discretionary flexibility regarding professional judgements made by the Care Coordinators, professional 
accountability to families can be attained, while meeting the needs of medically complex children.

\section{Summary}

The growth in size and increased medical complexity of this population have placed strains both on the health care system as well as the families affected. Family stress and burden have been reported throughout the literature and were highlighted by the Care Coordinators in this study (Hayes \& McElheran, 2002; McKeever, 1994; Ray, 2005; Snowdon \& Kane, 1995; Spalding, Hayes, Williams, \& McKeever, 2002; WardGriffin \& McKeever, 2000). Stress and burden result from performing duties that are above and beyond the usual parental responsibilities, financial losses due to time away from work and escalating medical costs, and an increase in social isolation. In an effort to alleviate these symptoms, the Care Coordinators attempt to allocate professional home and community care resources, but unfortunately face challenges due to the health human resource shortages experienced throughout the province. The health human resource shortages are more severe for professionals with a specialization in paediatrics.

Each of the Care Coordinators entered their position with the intent to provide optimal care and service to this population under the commitments and values of the organization. This study has demonstrated that the Care Coordinators are continually restricted by the home and community resources that are made available to them. Therefore, a struggle develops between managing demands of the organization and the needs of the clients. Unfortunately, due to the fact that there currently is no standardized assessment tool or eligibility criteria for this particular home and community care population, the organization is unable to demonstrate to policy-makers the apparent 
discrepancies between supply and demand of particular professional services. However, some Care Coordinators contend that these children and families are too unique to implement a standardized assessment tool and using such a tool might not take into consideration their professional knowledge and expertise.

\section{Study Implications}

\section{Policy}

Due to the current health care restructuring experienced in Ontario, there is a greater trend to providing health care within the home and community setting. As demonstrated by this study and others, there is a need to have a nursing workforce with paediatric specialization within the home and community setting prepared to provide care for an increasing number of medically complex children. Although there has been a greater emphasis on delivering health care in the home and community setting, Alameddine, Laporte, Baumann, O’Brien-Pallas, Croxford, Wang, et. al (2006) illustrated the significant health human resource shortages in this sector. In Ontario, between 1993 and 2003 , there was nearly a $31 \%$ drop in the number of registered nurses providing direct patient care in the home and community sector (Alameddine, Laporte, Baumann, O’Brien-Pallas, Croxford, Wang, et. al, 2006). Similarly, the number of registered nurses with paediatric knowledge and expertise has also decreased in this sector, especially in the rural areas of Ontario (Spalding, 2005). This health human resource issue greatly impacts the care received by the medically complex child. In order to address this issue of keeping these children adequately serviced in the home and community setting, policymakers need to allocate more funds or redistribute current funds to attract health care professionals to the home and community sector. 
There is a demonstrated need for policy-makers to understand the realities of the system level challenges that medically complex children and their families face in order to ensure access to essential professional home and community care services. Although increased funding is regarded as the solution to many home care issues, this research clearly indicates the directions for the future go far beyond funding. By drawing attention to the medically complex child and family's needs, and identifying those needs through data, paediatric driven organizational policies can be modeled and developed. With the development of public policies, accepted models of care can be established and the allocation of appropriate government funds and resources can be put in place in order to meet the needs of this population. Additionally, there is a need for the restructuring of the formal assessment process for families to receive home and community care services. The needs of medically complex children can be better met with the inclusion of families in decisions regarding care needs, and the implementation of a balanced approach, which utilizes a formal assessment tool such as the interRAI coupled with Care Coordinator discretion.

As discussed by the Care Coordinators, their caseloads range from 200 to 320 children, however not all of these are medically complex children. Other children may include those who have short-term developmental needs, in-school rehabilitation services, or acute/short-term medical needs due to accident or injury. By changing the current model of care, from one where the Care Coordinators are responsible for clients who live within a geographical area to one that Care Coordinators specialize on specific populations regardless of where they live, such as medically complex children, this may improve the care and management of home and community services for this population. 
Several benefits could arise from this shift in models of care. First, by having Care Coordinators focus on specific populations, assessments can be perfected, as the Care Coordinators will be assessing a particular population. Second, Care Coordinators will have the ability to remain up to date on the availability of professional home and community care services frequently utilized by their focus population, as well as inform the organization when demands for a particular service outweigh the supply. Third, there are numerous governmental, private, and charitable organizations that provide additional funding or support to children who have specific illnesses or diseases. The Care Coordinators would be able to assist families complete any appropriate applications and facilitate acquiring any additional documentation. As the Care Coordinators experience working with one specific population, they will be better able to recognize these opportunities and aid the family in completing any required applications.

The Care Coordinators in the study have numerous years of experience in the home and community care sector and in working with children and expressed their enthusiasm, passion, and desire for working with and helping this population. Without the proper home and community resources to overcome the challenges and demands as evidenced throughout the study, the Care Coordinators face difficulties in successfully fulfilling their roles in supporting medically complex children and the family in the home. It is imperative that governments recognize that the needs of this population are growing and the associated challenges of meeting these needs as articulated by the Care Coordinators. Ultimately, a greater understanding by policy-makers is required, as Care Coordinators and the families of medically complex children are faced with difficulties 
and challenges of navigating a system composed of multiple governmental ministries and departments and health human resource shortages.

\section{Research}

This study aimed to add to the limited research focusing on medically complex children who are being cared for in the home and community. Although it has been indicated that technological advancements have allowed for this shift in the site of care, it is evident from the literature that there has been little research focusing on the long-term supports required by parents. The literature also emphasizes the current reliance on the family's ability to provide the necessary health care for the medically complex child. Future research studies focusing on the importance of an assessment process which incorporates the family's needs is required. Additionally, these future research studies could examine how best to determine which professional home and community services are needed and demonstrate the optimal level of service. With this understanding, families could be more effectively supported in providing the necessary care to their medically complex child throughout the continuum of their care. It is evident from this study that further research is required to evaluate different models and approaches of care to adequately serve this population of medically complex children, taking into account the various factors influencing the family's ability to effectively care for their child.

\section{Limitations}

Although difficult to foresee potential limitations of the research study, there are a few that must be taken into consideration, which may hinder the results of the study. The study was conducted using a small purposeful sample of Care Coordinators whose role it is to assess, allocate and manage home and community care services for medically 
complex children and their families. Conducting a focus group with Care Coordinators, each of whom work independently in the community setting, social desirability may have influenced their responses regarding their decision-making processes when assessing, allocating and managing medically complex children and their families. As a result, this may have limited the data garnered during the focus group and the ability of the researcher to draw appropriate conclusions of their decision-making processes. In an attempt to minimize the effects of social desirability, the researcher ensured all participants anonymity and confidentiality throughout the entire research process.

It is recommended that the study be replicated with a larger sample of Care Coordinators across the province who are also responsible for assessing, allocating and managing home and community care services to this population. Findings may have differed as the different regions of the province may have presented differing issues, challenges, approaches, policies and protocols. Also, by garnering the perspectives of Care Coordinators working within paediatric acute care settings could have provided additional insights into the decision-making processes upon the medically complex child's discharge. Lastly, it is important to note that the perspectives of medically complex children and their families were not included in this research. By gaining their understanding and perspectives regarding the decision-making processes made by their Care Coordinator could have provided an addition element to the findings of the study.

In terms of qualitative research findings, these findings are not completely transferable and generalizable to other home and community care populations, but can be added to the limited research regarding the assessment, allocation, and management of medically complex children and their families in the home and community setting. 


\section{Conclusion}

This study adds to the understanding of the implications for providing efficient and effective professional services across the continuum of care for this continually growing medically complex children population in Ontario. As the site of health care shifts from institutional care to the home and community setting, the Care Coordinators are left responsible for assessing, allocating, and managing professional home and community care services for medically complex children and their families. The case study design was guided by the underlying framework that the Care Coordinators act as street-level bureaucrats. It was evident that the Care Coordinators have considerable discretion regarding the allocation of services, similar to that of street-level bureaucrats referred to by Lipsky (1980). Therefore, the Care Coordinators have discretionary power to allocate services and ultimately implement government policy on a daily basis. The Care Coordinators contend that their role requires flexibility during the decision-making process and should not be confined to the utilization of a standardized assessment tool such as the interRAI. Although flexibility is an important aspect when assessing and delivering home and community care services for a medically complex child, there is a need for guidelines and accountability measures. This would provide those who receive services an understanding of the decisions regarding the allocation of services and allow for an appeals process, if necessary.

It was demonstrated that Care Coordinators face many challenges in coordinating multiple professional home and community care services, through their expertise and discretionary power, to meet the needs of the family and medically complex child. Although this population has not gone unnoticed by the research community, further 
research is needed to keep pace with the continual growth and increasing complexity of this population in order for these children and families to genuinely benefit from the other medical advances regarding their care. 


\section{References}

Alameddine, M., Laporte, A., Baumann, A., O’Brien-Pallas, L., Croxford, R., Wang, S., Milburn, B., \& Deber, R. (2006). Where are nurses working? Employment patterns by sub-sector in Ontario, Canada. Healthcare Policy, 1(3), 65-86.

Alexander E., Rennick J.E., Carnevale F. \& Davis M. (2002). Daily struggles: living with long-term childhood technology dependence. Canadian Journal of Nursing Research 34 (4), 7-14.

Anderson, J. M. (2001). The politics of home care: Where is "home"? Canadian Journal of Nursing Research, 33(2), 5-10.

Appierto, L., Cori, M., Bianchi, R., Onofri, A., Catena, S., Ferrari, M., et al. (2002). Home care for chronic respiratory failure in children: 15 years experience. Pediatric Anesthesia, 12(4), 345-350.

Baranek, P. M., Deber, R. B., \& Williams, A. P. (2004). Almost home: Reforming home and community care in Ontario. Toronto, University of Toronto Press.

Beresford, B. (1996). Coping with the care of a severely disabled child. Health and Social Care in the Community. 4, 30-40.

Bremberg, S. (2000) Health promotion at Swedish child health centres. Acta Paediatrica, 89(31), 53-56.

Butterfield, P. G. (2001). Thinking upstream: Conceptualizing health from a population perspective. Community health nursing: Promoting health of populations (2nd ed., pp. 48-52). W.B. Saunders Company. 
Carnevale, F., Alexander, M., Davis, M., Rennick, J., \& Troini, R. (2006). Daily living with distress and enrichment: The moral experiences of families with ventilatorassisted children at home. Pediatrics, 117(1), 48-60.

Cavanagh S. (1997). Content analysis: concepts, methods and applications. Nurse Researcher, 4, 5-16.

Cohen, E., Friedman, J., Nicholas, D., Adams, S., and Rosenbaum, P. (2008). A home for medically complex children: the role of hospital programs. Journal for Healthcare Quality. 30, p. 7-15.

Community Care Access Centre. (2010). What we do. Retrieved from: http://www.ccacont.ca/Content.aspx?EnterpriseID $=15 \&$ Language ID $=1 \&$ MenuID $=137$

Creswell, J. W. (2007). Qualitative inquiry and research design: Choosing among five traditions. $\left(2^{\text {nd }}\right.$ ed.). Thousand Oaks, CA: Sage Publications, Inc.

Crossley, N. (2005). Key concepts in critical social theory. London, Sage Publications, Inc.

Denzin, N. K. \& Lincoln, Y. S., eds. (2005). The Sage Handbook of Qualitative Research, 3rd ed. Thousand Oaks, CA: Sage.

Doran, D.M., Harrison, M., Spence-Laschinger, H., Hirdes, J., Rukholm, E., Sidani, S., McGillis-Hall, L., \& Tourangeau, A., Cranley, L. (2006). The Relationship Between Nursing Interventions and Outcome Achievement in Acute Care and Long-Term Care. Research in Nursing \& Health, 29, 61-70. 
Edwards, E. A., O'Toole, M., \& Wallis, C. E. (2004). Sending children home on tracheostomy dependent ventilation: pitfalls and outcomes. Archives of Disease in Children, 89(3), 251-255.

Ellis, K., Davis, A., Rummery, K. (1999). Needs assessment, street-level bureaucracy and the new community care. Social Policy and Administration, 33(3), 262-280.

Ellis, J., Luiselli, J., Amirault, D., Byrne, S., O’Malley-Cannon, B., Taras, M., et al. (2002). Families of children with developmental disabilities: Assessment and comparison of self-reported needs in relation to situational variables. Journal of Developmental and Physical Disabilities, 14(2),191-201.

Falk-Rafael, A. (2005). Advancing nursing theory through theory-guided practice: The emergence of a critical caring perspective. Advances in Nursing Science, 28(1), $38-49$.

Hamilton Niagara Haldimand Brant LHIN. (2006). Building an Integrated Health Service Plan - Phase One. Retrieved from: http://www.hnhblhin.on.ca/uploadedFiles/Home_Page/Integrated_Health_Service Plan/LHIN-IHSP-ENG(1).pdf.

Hayes, V. E., Hollander, M. J., Tan, E. L. \& Cloutier, J. E. (1997). Services for Children with Special Needs in Canada. A report prepared for the Canadian Association for Community Care and Health Canada, October: Victoria, BC: Health Network, Canadian Policy Research Networks.

Health Canada. (2005). Overview of the Canada Health Act. Retrieved from: http://www.hc-sc.gc.ca/hcs-sss/medi-assur/overview-apercu/index_e.html.

Heaton, J., Noyes, J., Sloper, P., \& Shah, R. (2005). Families' experiences of caring for 
technology-dependent children: A temporal perspective. Health and Social Care in the Community, 13(5), 441-450.

Hollander, M. J. (2001). Substudy 1: Final report of the study on the comparative cost analysis of home care and residential care services. Ottawa, Canada: Health Transition Fund, Health Canada.

InterRAI. (2008). Clinical assessment protocols. Retrieved from: http://www.interrai.org/section/view/?fnode $=26$.

Kirby, M. (2002). The health of Canadians - The Federal role: Final Report. Ottawa, Ontario, Government of Canada.

Kirk, S. (1998). Families' experiences of caring at home for a technology-dependent child: a review of the literature. Child: Care, Health and Development 24(2), $101-114$.

Kirk S. (1999). Caring for children with specialized health care needs in the community: The challenges for primary care. Health \& Social Care in the Community 7(5), $350-357$.

Kirk, S. (2001). Negotiating lay and professional roles in the care of children with complex health care needs. Journal of Advanced Nursing 34, 593-602.

Krueger, R. A. (1998). Developing questions for focus groups. Thousand Oaks, CA: Sage.

Krueger, R. A. \& Casey, M. A. (2009). Focus groups: A practical guide for applied research (4th Ed.). Thousand Oaks, CA: Sage.

Kuster, P. A., Badr, L. K., Chang, B. L., Wuerker, A. K., \& Benjamin, A. E. (2004). Factors influencing health promoting activities of mothers caring for ventilator- 
assisted children. Journal of Pediatric Nursing: Nursing Care of Children and Families, 19(4), 276-287.

McKeever, P. (1994). Between women: Nurses and family caregivers. Canadian Journal of Nursing Research, 26(4), 15-21.

Ministry of Health and Long-Term Care. (2010). Local Health Systems Integration Act - 2006. Retrieved from:

http://www.elaws.gov.on.ca/html/statutes/english/elaws_statutes_06104_e.htm.

Morgan D.L. (1993). Successful Focus Groups: Advancing the state of the art. Newbury Park, CA: Sage.

Neundorf, K. (2002) The Content Analysis Guidebook. Sage Publications Inc., Thousand Oaks, CA.

Parker, G., Bhakta, P., Lovett, C., Olsen, R., Paisley, S., \& Turner, D. (2006). Paediatric home care: A systematic review of international evidence on costs and effectiveness. Journal of Health Services Research and Policy, 11(2), 110-119.

Patton, M.Q. (2002). Qualitative evaluation methods. Thousand Oaks, CA: Sage Publications, Inc.

Perrin, J. M., Romm, D., Bloom, S. R., Homer, C. J., Kuhlthau, K. A., Cooley, C., et al. (2007). A family-centered, community-based system of services for children and youth with special health care needs. Arch Pediatr Adolesc Med, 161(10), 933 936.

Quine, L. \& Pahl, J (1991) Stress and coping in mothers caring for a child with severe learning difficulties: A test of Lazurus' transactional model of coping. Journal of Community \& Applied Social Psychology, 1, 57-70. 
Ray, L. (2005). Categorical service allocation and barriers to care for children with chronic conditions. Canadian Journal of Nursing Research, 37(3), 86-102.

Romanko, E. (2005). Caring for children with bronchopulmonary dysplasia in the home setting. Home Healthcare Nurse, 23(2), 95-102.

Rosenbaum, P. (2008). The report of the paediatric complex care coordination expert panel. Ontario Ministry of Health and Long-Term Care. Retrieved from: http://www.health.gov.on.ca/transformation/wait_times/providers/reports/paed_re p_20080501.pdf.

Salib, D. (2007). Home and community care for children and youth. Unpublished manuscript.

Sherman, B.R. (1995). Impact of home-based respite care on families of children with chronic illnesses. Children's Health Care, 24(1), 33-45.

Sidani, S., Doran, D., and Mitchell, P. (2004). A theory-driven approach to evaluating quality of nursing care. Journal of Nursing Scholarship, 36(1), 60-65.

Snowdon, A. W. \& Kane, D. J. (1995). Parental needs following the discharge of a hospitalized child. Health and Social Care in the Community, 9(2), 108-117.

South West LHIN (SW LHIN). (2006). The South West LHIN - Integrated Health Service Plan (IHSP). Retrieved from: http://www.southwestlhin.on.ca/uploadedFiles/Public_Community/Integrated_Heal th_Service_Plan/2006_IHSP/Integrated\%20Health\%20Service\%20Plan.pdf.

Spalding, K. L. (2005). Policy by default: How changes in Ontario's home care sector have impacted providers, children and families. Unpublished doctoral dissertation. University of Toronto, Toronto. 
Spalding, K.L., Hayes, V.E., Williams, A.P., \& McKeever, P. (2002). Services for children with special needs and their families: Analysis of interfaces along the continuum of care. Technical report 5. Victoria, British Columbia: Hollander Analytical Services Inc. Retrieved from: www.hollanderanalytical.com/downloads/continuum-tech-5.pdf.

Speziale, H., \& Carpenter, D. (2007). Qualitative research in nursing. Advancing the humanistic imperative. ( $4^{\text {th }}$ ed.). Philadelphia, PA: Lippincott, Williams \& Wilkins. Statistics Canada. (2003). Participation and activity limitation survey, 2001. Statistics Canada: Housing, Family and Social Statistics Division: Ottawa, ON: Author.

Stake, R. E. (1995). The art of case study research. Thousand Oaks, CA: Sage Publications, Inc.

Wang, K. K. \& Barnard, A. (2004) Technology-dependent children and their families. Journal of Advanced Nursing, 45(1), p. 36-46

Ward-Griffin, C. \& McKeever, P. (2000). Relatioships between nurses and family caregivers: Partners in care? Advances in Nursing Science, 22(3), 89-103.

Williams, A.P., Deber, R.B., Baranek, P., \& Gildiner, A. (2001). From Medicare to home care: globalization, state retrenchment and the profitization of Canada's health care system. In: Armstrong, P., Armstrong, H. and Coburn, D. (eds.), Unhealthy times: Political economy perspectives on health and health care in Canada. Toronto: Oxford University Press, 7-30.

Wise, P.H. (2004). The Transformation of Child Health in the United States. Health Affairs, 23(5), 9-26. 
Wong, D. L. (1991). Transition from hospital to home for children with complex medical care. Journal of Pediatric Oncology Nursing, 8(1): 3 - 9.

Yantzi, N. M., Rosenberg, M. W., \& McKeever, P. (2007). Getting out of the house: The challenges mothers face when their children have long-term care needs. Health $\&$ Social Care in the Community, 15(1), 45-55.

Yin, R.K. (1994). Case study research - Design and methods ( $2^{\text {nd }}$ Edition). Thousand Oaks, California, Sage Publications, Inc. 
Appendix A

Consent for Participation in Research

Study Title:

\section{Children and Youth with Long-Term Care Needs \\ (CCAC Case Manager Consent Form)}

\section{Principal Investigator:}

David Salib, RN, MN (student)

Master of Nursing Student

Daphne Cockwell School of Nursing

Ryerson University,

350 Victoria Street, Toronto, Ontario, M5B 2K3

e-mail: dsalib@ryerson.ca

\section{Thesis Supervisor:}

Karen Spalding, $\mathrm{PhD}$.

Associate Professor and Director, Master of Nursing - Research and Graduate

Studies

Daphne Cockwell School of Nursing

Ryerson University

350 Victoria Street, Toronto, Ontario, M5B 2K3

Phone: 416-979-5000 ext.6307; kspaldin@ryerson.ca

\section{Purpose of the Study:}

The purpose of this study is to explore and understand how Care Coordinators in a CCAC make decisions regarding the allocation and delivery of home care services to children with medically complex care needs.

\section{Description of the Study:}

This study is qualitative in nature and will result in a greater understanding of the allocation and delivery of home and community care services to families caring for medically complex children. Focus group questions will ask about the 
following: use of assessment tools to determine allocation and delivery of services, coordination and integration of services, health human resource issues, the availability of respite care, any policy implications for children with special needs, and any future directions.

If you decide to participate in this study you will be part of a focus group. We will ask you to meet on one occasion with the researcher for a discussion about home and community care service allocation and delivery for the population of medically complex children your organization serves. You will be asked to provide your thoughts regarding the following: various assessment tools utilized to allocate services; the level of influence these assessment tools have on final decisions; other decision-making processes utilized in your organization to determine the allocation of home care services; and the amount and types of services children and families receive.

\section{Risks and Benefits of the Study:}

No significant risks are foreseen for participants. If a participant starts to feel uncomfortable about answering questions pertaining to the policies and guidelines they must follow regarding allocation of home care resources, we will stop the focus group at their request and they can leave. A benefit for participants will be the sense of contribution improvement home care for children and families. Previously those who have participated in similar research have voiced appreciation for being asked to participate, as it assists them in evaluating their own thoughts and ideas and they enjoy seeing the summary of findings with their own input together with that of others. As a research participant you are free to withdraw at any point, either temporarily or permanently, or to refuse to participate from the outset. The time commitment expected of you as a participant is approximately 45 minutes. 


\section{Confidentiality:}

All data will be kept strictly confidential by the researcher. The audiotapes and transcripts will be secured in a locked cabinet for 5 years. All electronic data generated by the study will be password protected and encrypted. The transcriptions of each focus group will be coded and no identifiable information will be on the transcriptions.

All data will be kept strictly confidential by the researcher; however, confidentiality cannot be guaranteed since you are meeting face to face as a focus group. However, we will ask the participants not to disclose who participated in the focus group and your name will not appear on any final document and names will not be recorded on the transcripts.

\section{Costs and/or Compensation for Participation:}

No incentive or payment is offered for participation in this study.

\section{Voluntary Nature of Participation:}

Participation in this study is voluntary. Your choice of whether or not to participate will not influence your future relations with the research team. If you decide to participate, you are free to withdraw consent and to stop your participation at any time. At any particular point in the study, you may refuse to answer any particular question or stop participating altogether.

\section{Questions about the Study:}

The Principal Investigator in this research is David Salib, RN, School of Nursing, Ryerson University, Toronto), and if you have any concerns or questions about 
the research you may call his Thesis Supervisor, Karen Spalding at 416-979-5000 ext.6307 or e-mail David at dsalib@ryerson.ca

If you have questions regarding your rights as a human subject and participant in this study, you may contact the Ryerson University Research Ethics Board for information.

\author{
Research Ethics Board \\ c/o Office of the Vice President, Research and Innovation \\ Ryerson University \\ 350 Victoria Street \\ Toronto, ON M5B 2K3 \\ 416-979-5042
}

\title{
Agreement to Participate:
}

I understand that:

- My participation will consist of one meeting that will take approximately 45 minutes.

- I am free to participate or not, no one will know from the researchers whether I participate, and any participation will be kept completely confidential.

- I will not benefit directly from participating, though I may benefit from reflecting on my own experiences as well as learning more about those of others involved in the provision of home and community health care for children and youth.

- There are minimal risks associated with this research.

- Every effort will be made to ensure that my participation will be kept confidential. In public presentations of the research (in any form), my name will not be associated with any quotes or opinions without my explicit permission;

- I will not be compensated for my participation.

My signature below indicates that I have read the information in this agreement and have had a chance to ask any questions you have about the study. My signature also indicates that I agree to be in the study and I am aware that I can 
change my mind and withdraw my consent to participate at any time. I have been given a copy of this agreement.

Name of Participant (please print)

Signature of Participant

Date

Email Address

Name of Witness (please print)

Signature of Witness

Date

Agreement to be Audiotaped:

By signing below I agree to have the focus group audiotaped:

Name of Participant (please print)

Signature of Participant

Date 
Date 
Appendix B

Children and Youth with Long-Term Care Needs (CCAC Case Manager Demographics)

Title/Position:

Professional Designation:

Number of Years in Current Position:

Number of Years in Home Care:

Average Caseload:

Previous Employment History: 


\section{Appendix C}

\section{Children and Youth with Long-Term Care Needs (CCAC Case Manager Interview Guide)}

1) Could you please describe the range of clients/kids/families found on your caseloads

2) How has the child and youth home and community care population changed over the time that you have been a Care Coordinator? (caseloads, severity)

b) Have the services being provided changed?

c) Have you noticed any increases or decreases in the demands for home and community care services?

3) Could you please go over the assessment process for a new referral from the initial intake to the allocation and delivery of services, highlighting any tools during the decision-making process.

b) What influence do parent's play during the decision-making process regarding service allocation?

4) Could you please describe your experiences as a Care Coordinator for this client population. (Opportunities for growth or change, challenges or barriers commonly faced)

b) Experiences with other agencies, parents, services providers

5) Could you please describe your role in monitoring services that are delivered in the home.

b) How often are children and their families followed-up? (ie. Whether clients are actually receiving services, are the services effectively meeting the needs of the client, how are clients' managing?) 
6) Are you aware of any formal evaluation of the program from the clients perspective? (ie. results in terms of: client's health status outcomes, perceived client satisfaction, perceived caregiver satisfaction, quality of life, effect on informal caregiver burden, effect on out-of pocket expenses for client, effect on paid professional caregivers, effect on paid non-professional caregivers).

7) Could you describe how/if the implementation of the LHINs in 2007 have affected you ability to provide services to this population.

8) If given the opportunity, how would you transform delivery of home and community services for children and youth across the GTA

Thank you again for your participation. 
Appendix D - Data Analysis: Development of Codes

\begin{tabular}{|c|c|c|}
\hline First Set of Codes -23 Codes & Second Set of Codes - 18 Codes & Final Set of Codes - 11 Codes \\
\hline 1. Sicker population/living longer & Sicker population/living longer & Sicker population/living longer \\
\hline 2. Increasing \# of services clients require & Caregiver burden/child comfort levels & Caregiver burden/child comfort levels \\
\hline 3. Caregiver burden/child comfort levels & Last stop for families & Communication with service providers/parents \\
\hline 4. Palliative clients & Communication with service providers/parents & Decision-making \\
\hline 5. Transitional issues & Communication between care coordinators & Usefulness of assessment tools \\
\hline 6. Falling through the cracks & Decision-making & $\begin{array}{l}\text { System Level Challenges } \\
\text { - Lack of available services/health human resources } \\
\text { - Waitlists } \\
\text { - Differences in policies/protocols }\end{array}$ \\
\hline 7. Last stop for families & Usefulness of assessment tools & Economic downturn \\
\hline $\begin{array}{l}\text { 8. } \\
\text { Communication with service } \\
\text { providers/parents }\end{array}$ & Challenges to delivering services & Team-based approach \\
\hline $\begin{array}{l}\text { 9. Little communication between care } \\
\text { coordinators }\end{array}$ & Lack of available services & Quality assurance \\
\hline 10. Usefulness of assessment tools & Health human resources issues & Changes since the implementation of the LHINs \\
\hline 11. Health human resource issues & Waitlists & $\begin{array}{l}\text { Future transformation of home and community care } \\
\text { services }\end{array}$ \\
\hline 12. Lack of rural resources & Economic downturn & \\
\hline 13. Lack of available services/supplies & Differences in policies/protocols & \\
\hline 14. Waitlists & CCAC caseload assignments/workloads & \\
\hline 15. Differences between policies/protocols & Team-based approach & \\
\hline 16. Economic downturn & Formal evaluation for parents & \\
\hline 17. CCAC caseload assignments/workloads & Changes since implementation of the LHINs & \\
\hline 18. Care coordinator professional background & Future transformation of services & \\
\hline 19. Team collaboration & & \\
\hline 20. Monitoring of service providers & & \\
\hline 21. Formal evaluation for parents & & \\
\hline $\begin{array}{l}\text { 22. Changes since implementation of the } \\
\text { LHINs }\end{array}$ & & \\
\hline 23. Future transformation of services & & \\
\hline
\end{tabular}

